\title{
Asymmetric Responses of Tropical Precipitation during ENSO
}

\author{
Chia ChOU \\ Research Center for Environmental Changes, Academia Sinica, and Department of Atmospheric Sciences, National Taiwan \\ University, Taipei, Taiwan \\ Min-Hui Lo \\ Research Center for Environmental Changes, Academia Sinica, Taipei, Taiwan
}

(Manuscript received 21 February 2006, in final form 23 October 2006)

\begin{abstract}
In response to the zonally symmetric El Niño-Southern Oscillation forcing, hemispherically asymmetric tropical precipitation anomalies associated with the Hadley circulation are found. In boreal spring after an El Niño peak phase, positive tropical precipitation anomalies occur in the Southern Hemisphere, while negative precipitation anomalies are found in the Northern Hemisphere. This zonal asymmetry is more apparent in the El Niño decaying phase than in the El Niño growing phase. The maximum amplitude of this zonal asymmetry lags one season behind the maximum SST anomalies over the tropical eastern Pacific. This lagged response of the asymmetry is mainly because of the tropical precipitation outside the tropical eastern Pacific, which is associated with the SST and tropospheric temperature anomalies outside the tropical eastern Pacific. A combination of the effect associated with the anomalous gross moist stability and the effect of the horizontal moist static energy (MSE) transport is responsible for the asymmetry. The above effects are associated with the seasonal migration of the Hadley circulation. Warm SST and tropospheric temperature anomalies increase the low-level moisture in the Tropics. In the effect associated with anomalous gross moist stability, the tropical precipitation over the ascending branch of the Hadley circulation is enhanced because of the decrease of effective moist stability, which is induced by the increase of low-level moisture. This enhancement associated with the Hadley circulation reduces the low-level moisture over the descending branch and creates a meridional moisture gradient. In the effect of the horizontal MSE transport, the tropical precipitation anomalies over margins of the ascending branch is reduced by dry advection from the descending branch, which is associated with mean Hadley circulation.
\end{abstract}

\section{Introduction}

Sea surface temperature (SST) anomalies associated with El Niño-Southern Oscillation (ENSO) induce a complex pattern of tropical precipitation anomalies not only over local regions, but also over remote areas (Curtis and Adler 2003; Dai and Wigley 2000; Kiladis and Diaz 1989; Rasmusson and Arkin 1993; Ropelewski and Halpert 1987, 1996; Wallace et al. 1998). During the El Niño mature phase, warm SST anomalies over the equatorial eastern Pacific enhance convection and positive precipitation anomalies over the equatorial central and eastern Pacific. To the north and south of this en-

Corresponding author address: Chia Chou, Research Center for Environmental Changes, Academia Sinica, P.O. Box 1-48, Taipei 11529, Taiwan.

E-mail: chiachou@rcec.sinica.edu.tw hanced precipitation region a horseshoe pattern of negative precipitation anomalies are found (Ropelewski and Halpert 1987). A reduction of rainfall is also found over the Maritime Continent and the western Pacific (Chang et al. 2004; Hendon 2003; Lau and Nath 2003; McBride and Nicholls 1983; Ropelewski and Halpert 1987; Wang et al. 2000). To the north of these negative precipitation anomalies over the western Pacific, positive precipitation anomalies occur along the east coast of east Asia. These positive precipitation anomalies are associated with the weakening of the Asian winter monsoon and the strengthening of the spring rainfall over east Asia (Dai and Wigley 2000; Jiang et al. 2003; Lau and Nath 2003). Other negative precipitation anomalies are found over the equatorial South America and the Atlantic intertropical convergence zone (ITCZ; Chiang et al. 2002; Foley et al. 2002; Nobre and Shukla 1996; Neelin and Su 2005). Mechanisms for these tropi-

DOI: 10.1175/JCLI4197.1

(C) 2007 American Meteorological Society 
cal precipitation anomalies involved with ENSO teleconnection have been discussed by many studies (e.g., Giannini et al. 2001; Soden 2000; Su et al. 2001; Su and Neelin 2002; Trenberth et al. 1998; Wallace et al. 1998). One of those mechanisms involves teleconnection via tropospheric temperature changes. Tropospheric temperature anomalies associated with El Niño spread over the Tropics via wave dynamics (Wallace et al. 1998) and induce remote tropical precipitation anomalies by interacting with moist convection (Chiang and Sobel 2002; Neelin et al. 2003, NCS03 hereafter).

From a hemispheric point of view, the precipitation anomalies associated with ENSO present new and interesting results. One example is the hemispheric symmetry of the El Niño-enhanced precipitation anomalies in the midlatitudes (Seager et al. 2005). In the Tropics, on the other hand, the El Niño-induced precipitation anomalies show a very different distribution: an asymmetry between the Southern and Northern Hemispheres (Fig. 1b). In the boreal spring, when the precipitation asymmetry is a maximum, the Southern Hemisphere average of tropical precipitation anomalies is positive, while the Northern Hemisphere average is negative. This asymmetry is also found in tropical moisture anomalies (Fig. 1c). During an El Niño event, the main forcing is the warm SST anomalies over the equatorial eastern Pacific, which are roughly symmetric to the equator, with positive SST anomalies on both sides of the equator throughout the entire El Niño period (Fig. 1a). The symmetric SST anomalies are particularly pronounced over the Niño-3.4 region $\left(5^{\circ} \mathrm{S}-5^{\circ} \mathrm{N}, 170^{\circ}-\right.$ $120^{\circ} \mathrm{W}$ ), where they are the strongest. Symmetry is also found in tropical tropospheric temperature anomalies, which is another possible forcing for inducing the tropical precipitation anomalies (Chiang and Sobel 2002; NCS03). During El Niño, positive tropospheric temperature anomalies are found over both the Northern and Southern Hemispheres. Overall, the El Niño forcings in SST and tropospheric temperature anomalies are symmetric to the equator, while the responses to the forcings in tropical precipitation and moisture are asymmetric to the equator.

The warm SST anomalies show a temporal symmetry between the El Niño growing and decaying phases, decaying away from the El Niño mature phase. The El Niño mature phase with the maximum SST anomalies over the equatorial eastern Pacific usually occurs in winter [December-February (DJF)]. The El Niño growing phase (year 0) is defined as the year before the mature phase, while the El Niño decaying phase (year 1 ) is defined as the year after the mature phase, following a conventional notation (Rasmusson and Carpenter 1982). On the other hand, the maximum tropical tro-
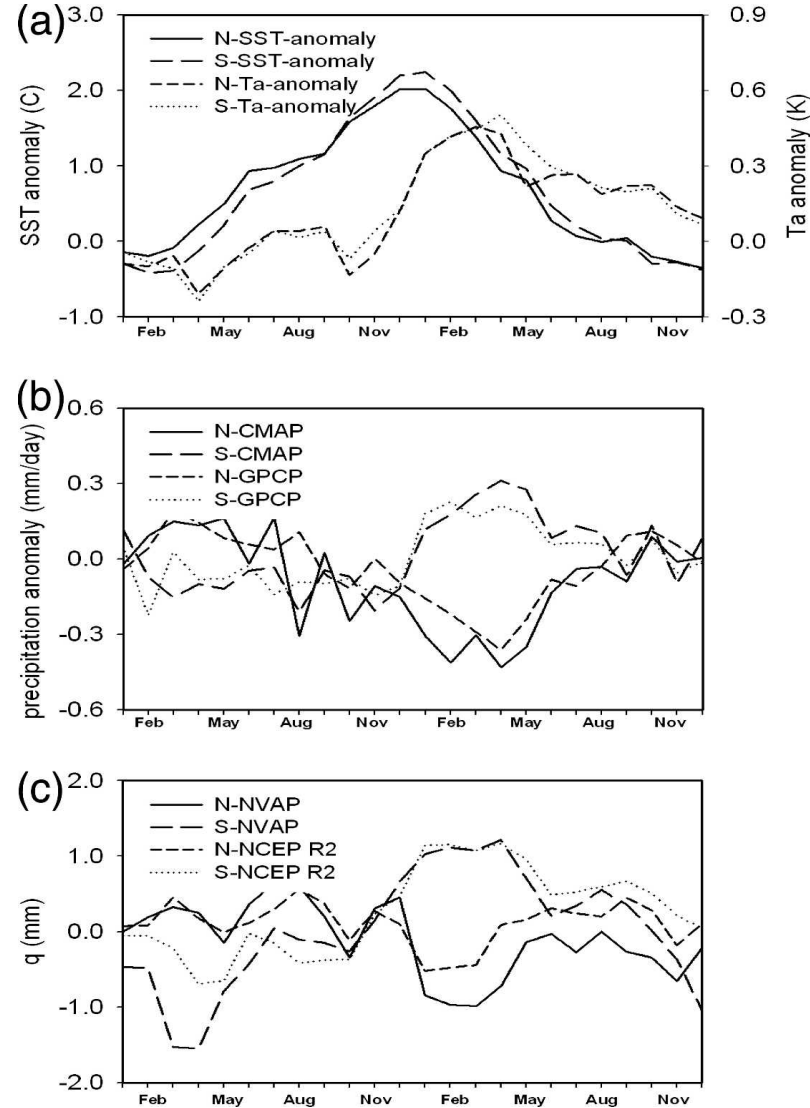

FIG. 1. Composites of the El Niño-induced anomalies: (a) SST and tropospheric temperature, (b) precipitation, and (c) tropospheric moisture. All, except the SST anomalies, are averaged over the Tropics $\left(30^{\circ} \mathrm{S}-30^{\circ} \mathrm{N}, 0^{\circ}-360^{\circ}\right)$. The SST anomalies are averaged over the Niño-3.4 region $\left(5^{\circ} \mathrm{S}-5^{\circ} \mathrm{N}, 170^{\circ}-120^{\circ} \mathrm{W}\right)$. Solid lines are for (a) SST, (b) CMAP precipitation, and (c) NVAP moisture averaged over the Northern Hemisphere; long-dashed lines are averaged over the Southern Hemisphere. Short-dashed lines are for (a) tropospheric temperature, (b) GPCP precipitation, and (c) NCEP2 moisture averaged over the Northern Hemisphere; dotted lines are averaged over the Southern Hemisphere.

pospheric temperature anomalies occur in spring of year 1 (February-May), which is a one-season lag to the El Niño mature phase. The lag response of tropospheric temperature anomalies to the El Niño SST anomalies has been discussed in several studies (e.g., Kumar and Hoerling 2003; Sobel et al. 2002; Su et al. 2005). The tropical precipitation anomalies also show a phase lag to the maximum SST anomalies, with maximum asymmetry occurring in spring of year 1 . Moreover, the asymmetry of the tropical precipitation anomalies is found only in year 1 , not in year 0 , with a temporal asymmetry between the El Niño growing and decaying phases.

What mechanisms induce the spatial and temporal asymmetry in the hemispheric average of the tropical 
precipitation changes? We would like to answer this question in this study. The data and model used in this study are described in section 2. Section 3 examines observations regarding the asymmetry of the tropical precipitation anomalies. In section 4, budgets of moisture and moist static energy (MSE) are analyzed to understand the mechanisms of the asymmetry. El Niño impacts on local and remote areas are examined in section 5 , followed by a discussion and conclusions.

\section{Data and model}

\section{a. Data}

To examine the precipitation changes, two of the most extensively used datasets - the Climate Precipitation Center Merged Analysis of Precipitation (CMAP; Xie and Arkin 1997) and the Global Precipitation Climatology Project (GPCP; Adler et al. 2003) - are used here. Both datasets are of the monthly precipitation for 1979-2004 with a resolution of $2.5^{\circ} \times 2.5^{\circ}$. The SST data use an optimum interpolation SST analysis to derive the Advanced Very High Resolution Radiometer for 1982-2004, with a resolution of $1^{\circ} \times 1^{\circ}$ (Reynolds et al. 2002). The tropospheric temperature is from Microwave Sounding Unit channel 2 for 1979-2004 with a resolution of $2.5^{\circ} \times 2.5^{\circ}$ (Mears et al. 2003). The total column water vapor $(\mathrm{mm})$ is from the National Aeronautics and Space Administration Water Vapor Project (NVAP) for 1988-2001 with a resolution of $1^{\circ} \times 1^{\circ}$ (Randel et al. 1996). Other fields, such as moisture transport and heat fluxes, are derived from 26-yr (19792004) reanalysis data from the National Centers for Environmental Prediction-Department of Energy (NCEP-DOE) (hereafter NCEP2; Kanamitsu et al. 2002), with a resolution of $2.5^{\circ} \times 2.5^{\circ}$. Because the NVAP total column water vapor does not include the period of the 1982/83 El Niño, the NCEP2 moisture is used in budget analysis. All of the data are monthly averages, except for moisture and MSE advection. In the calculation of those advections, 6-hourly data are used to include the contribution of transients. For consistency, all of the terms in the moisture and MSE equations, including precipitation, are all in watts per square meter. Precipitation, with units of watts per square meter, divided by 28 is equivalent to millimeters per day.

In this study, we chose the 1982/83 El Niño event as an example because it is a typical El Niño with strong SST anomalies. The 1999/2000 La Niña is also used for comparison. Composites of the El Niño-induced anomalies shown in Fig. 1 are from 1982/83, 1986/87, 1991/92, and 1997/98 for all variables except the NVAP tropospheric moisture anomalies, which are from 1991/ 92 and 1997/98 because of the data length.

\section{b. Model and experiment design}

To examine mechanisms for the asymmetry of tropical precipitation anomalies, a coupled oceanatmosphere-land model of intermediate complexity (Neelin and Zeng 2000; Zeng et al. 2000, ZNC hereafter) with prescribed divergence of ocean heat transport ( $Q$ flux) is used (Chou et al. 2001). Based on the analytical solutions derived from the Betts-Miller moist convective adjustment scheme (Betts and Miller 1993), typical vertical structures of temperature, moisture, and winds for deep convection are used as leading basis functions for a Galerkin expansion (Neelin and $\mathrm{Yu}$ 1994; Yu and Neelin 1994). The resulting primitive equation model makes use of constraints on the flow by quasi-equilibrium (QE) thermodynamic closures [the quasi-equilibrium tropical circulation model with a single vertical structure of temperature and moisture for deep convection (QTCM1)]. Because the basis functions are based on vertical structures associated with convective regions, these regions are expected to be well represented and similar to a GCM with the Betts-Miller moist convective adjustment scheme. Far from convective regions, QTCM1 is a highly truncated Galerkin representation equivalent to a two-layer model. A cloud radiation scheme (Chou and Neelin 1996; ZNC), simplified from the full GCM radiation schemes (Harshvardhan et al. 1987; Fu and Liou 1993), is included. Deep convection and cirrocumulus/ cirrostratus cloud fraction is estimated by an empirical parameterization (Chou and Neelin 1999). A simple formula is used to obtain atmospheric boundary layer winds under assumptions of a steady state and a vertically homogeneous mixed layer with fixed height (Stevens et al. 2002). An intermediate land surface model (ZNC) is used to simulate interaction between the atmosphere and land surface. This model simulates processes such as evapotranspiration and surface hydrology in a single land surface layer for calculating energy and water budgets. Soil moisture is balanced by precipitation, evaporation, surface runoff, and ground runoff. QTCM, version 2.3, is used here, with the solar radiation scheme slightly modified using the new $\mathrm{Fu}$ and Liou (1993) radiation scheme.

The experiment design in this study is similar to that used in Chou and Neelin (2004, CN04 hereafter). To examine mechanisms that induce the temporal and spatial asymmetry of tropical precipitation anomalies during ENSO, the prescribed 1982-83 SST over the tropical eastern Pacific $\left(30^{\circ} \mathrm{S}-30^{\circ} \mathrm{N}\right.$; east of date line) is used as a forcing, and the mixed layer ocean is used outside the tropical eastern Pacific. Differences between this simulation and a control experiment with climatological 
SST prescribed over the same eastern Pacific region (STND runs) will show impacts of the 1982/83 El Niño SST anomalies. To understand the effects of the gross moist stability (Yu et al. 1998), a similar pair of experiments but with fixed gross moist stability (fixed- $M$ runs) is performed. To examine the effect of the horizontal MSE transport, the seasonal climatology of the horizontal MSE transport obtained from the climatological SST experiment is also used in a pair of experiments similar to the STND runs [fixed-advtq runs; fixed $-\mathbf{v} \cdot \boldsymbol{\nabla}(T+q)$ in (5) in section 4], suppressing the effect of the anomalous horizontal MSE transport. Another pair of experiments with the 1982-83 SST and the SST climatology prescribed outside the tropical eastern $\mathrm{Pa}$ cific and the mixed layer ocean within the tropical eastern Pacific (remote SST runs) is used to estimate the contribution of the SST outside the tropical eastern Pacific to the tropical precipitation anomalies. Meanwhile, to estimate the contribution of the tropospheric temperature anomalies, the tropospheric temperature anomalies induced by the 1982/83 El Niño and the tropospheric temperature climatology are used, respectively, in the calculation of convective available potential energy (CAPE runs). The CAPE runs use the prescribed SST climatology for all oceans in the world. All experiments are averaged over $20 \mathrm{yr}$.

\section{Observation analysis}

To further investigate the asymmetry of tropical precipitation anomalies shown in Fig. 1b, zonally averaged $\left(0^{\circ}-360^{\circ}\right) \mathrm{SST}$, tropospheric temperature and water vapor, and precipitation anomalies induced by the 1982/ 83 El Niño are shown in Fig. 2. The warm SST anomalies extend a little more poleward over the Southern Hemisphere than the Northern Hemisphere between November of year 0 and April of year 1. However, the warm SST anomalies still dominate tropical oceans with the maximum SST anomalies at the equator. For temporal variation, the warm SST anomalies appear around August of year 0, reach the maximum strength in January of year 1, and disappear around August of year 1 . Thus, the SST anomalies are roughly symmetric between years 0 and 1 . For the tropospheric temperature, the zonally averaged anomalies are also roughly symmetric to the equator, but their temporal variation is different from the SST anomalies. The warm tropospheric temperature anomalies quickly reach the maximum within one season, but the anomalies last for two seasons after reaching the maximum. The warm tropospheric temperature anomalies occur mostly in year 1 and the maximum anomalies are around March of year 1 , which is a one-season lag to the maximum SST anomalies. The lagged relation between the maximum SST and tropospheric temperature anomalies has been discussed in several studies (e.g., Kumar and Hoerling 2003; Sobel et al. 2002; Su et al. 2005).

As possible forcings for the tropical precipitation anomalies associated with El Niño, both main SST and tropospheric temperature anomalies have the same sign on both sides of the equator. Responding to these forcings, however, the tropical precipitation anomalies shown in Fig. 2c have a very different spatial distribution. Main positive precipitation anomalies appear around October of year 0 near the equator, move southward to around $10^{\circ} \mathrm{S}$ in February-April of year 1, and then move northward to $10^{\circ} \mathrm{N}$ around August of year 1 . To the north of these positive precipitation anomalies, negative precipitation anomalies are also found, with a similar meridional movement. Most positive precipitation anomalies occur in the Southern Hemisphere, while the negative precipitation anomalies are in the Northern Hemisphere. This dipole pattern of the precipitation anomalies mainly occurs in year 1 and is consistent with the asymmetry of the hemispherically averaged tropical precipitation anomalies shown in Fig. 1b. The meridional movement of the tropical precipitation anomalies seems to follow the seasonal movement of the mean convection zones, defined as mean precipitation over $4 \mathrm{~mm} \mathrm{day}^{-1}$ (the thick dark line in Fig. 2c). The meridional movement of the zonally averaged mean convection zone is associated with the Hadley circulation, so this result implies that the Hadley circulation may play a role in the asymmetry of the tropical precipitation change. The zonal average of the tropospheric moisture anomalies shows similar spatial asymmetry to the precipitation anomalies, but the positive and negative moisture anomalies spread wider meridionally than the precipitation anomalies (Figs. 2c and 2d). The dipole pattern of the moisture anomalies is found mainly in the period of January-April of year 1.

To examine the meridional movement of the tropical precipitation anomalies more closely, the period of 1999-2000, which is dominated by La Niña, is used as another example. The SST and tropospheric temperature anomalies are over almost the entire 2-yr period. The cold SST anomalies are much more symmetric to the equator than the 1982-83 warm SST anomalies shown in Fig. 2a. This implies that the weak asymmetric SST anomalies shown in Fig. 2a should not be a main cause for inducing the asymmetry of the tropical precipitation anomalies. The tropospheric temperature anomalies are also spatially symmetric to the equator (Figs. 3a and 3b). Note that the SST and tropospheric temperature anomalies are negative in this case, so the 
(a) $\mathrm{SST}^{\prime}$

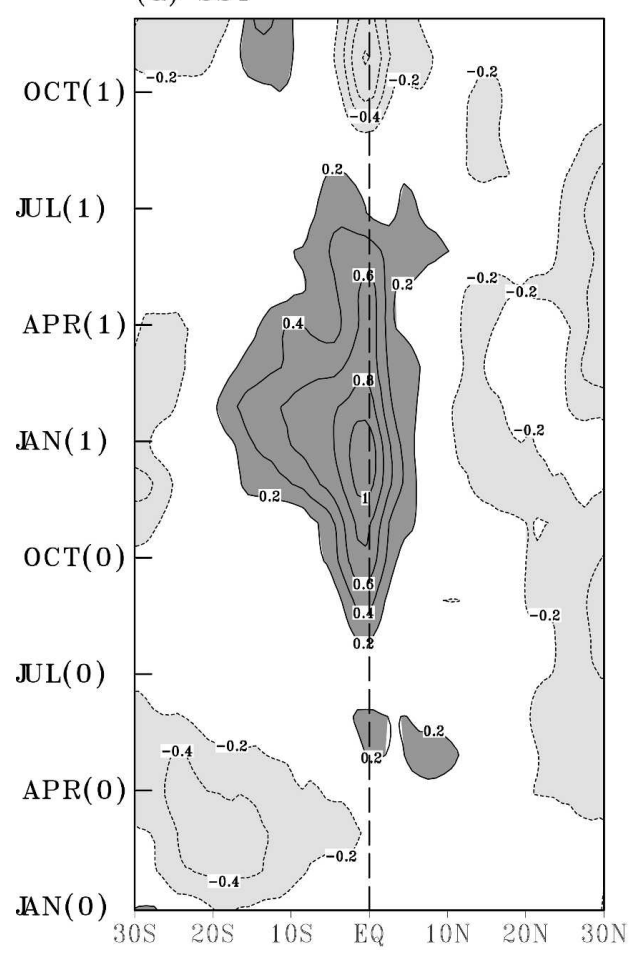

(c) $\mathrm{p}^{\prime}$

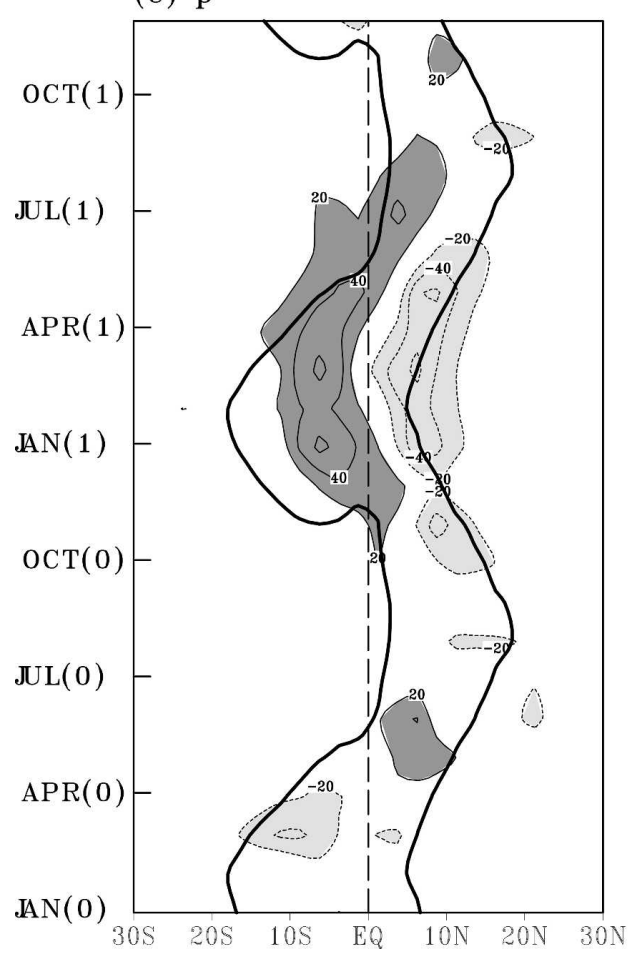

(b) $\mathrm{Ta}^{\prime}$

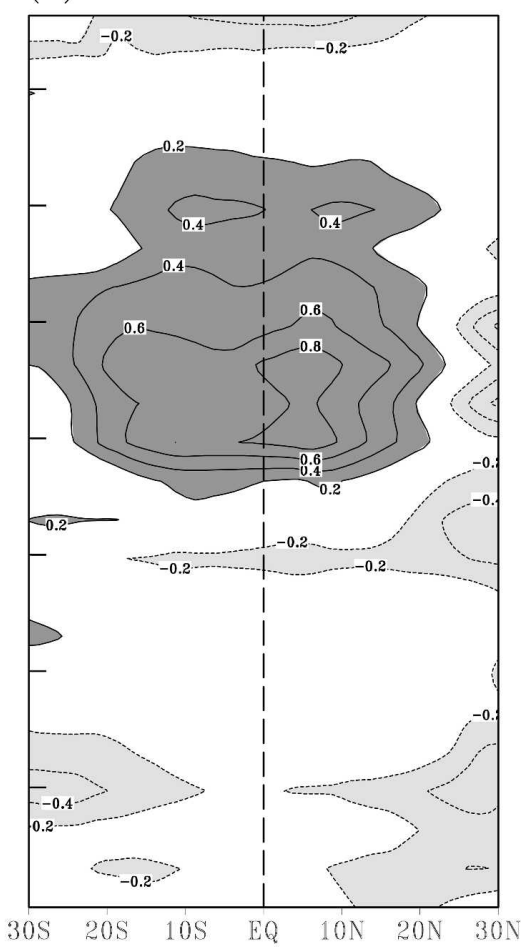

(d) $\mathrm{q}^{\prime}(\mathrm{NCEP} 2)$

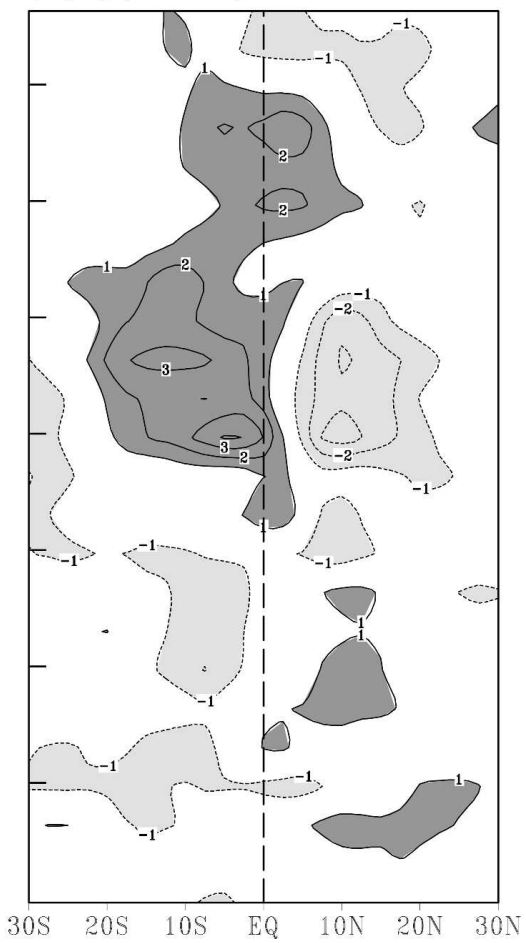

FIG. 2. Zonally averaged anomalies over $0^{\circ}-360^{\circ}$ for the $1982 / 83$ El Niño: (a) SST (K), (b) tropospheric temperature (K), (c) CMAP precipitation $\left(\mathrm{mm} \mathrm{day}^{-1}\right)$, and (d) NCEP2 moisture $(\mathrm{mm})$. The thick solid line in (c) is the $120 \mathrm{~W} \mathrm{~m}^{-2}$ contour of precipitation climatology. 
(a) $\operatorname{SST}^{\prime}(1999-2000)$

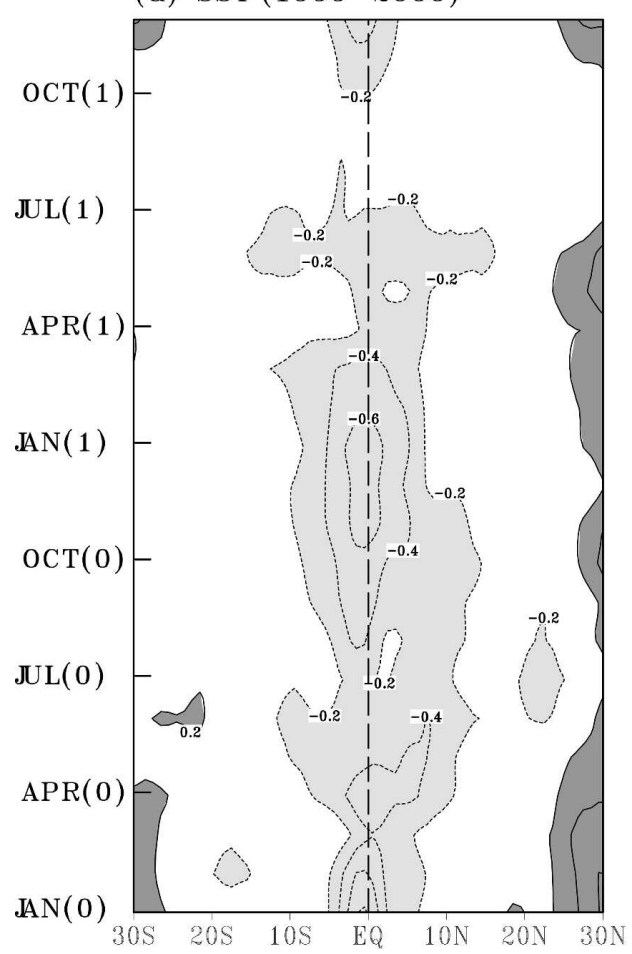

(c) p'

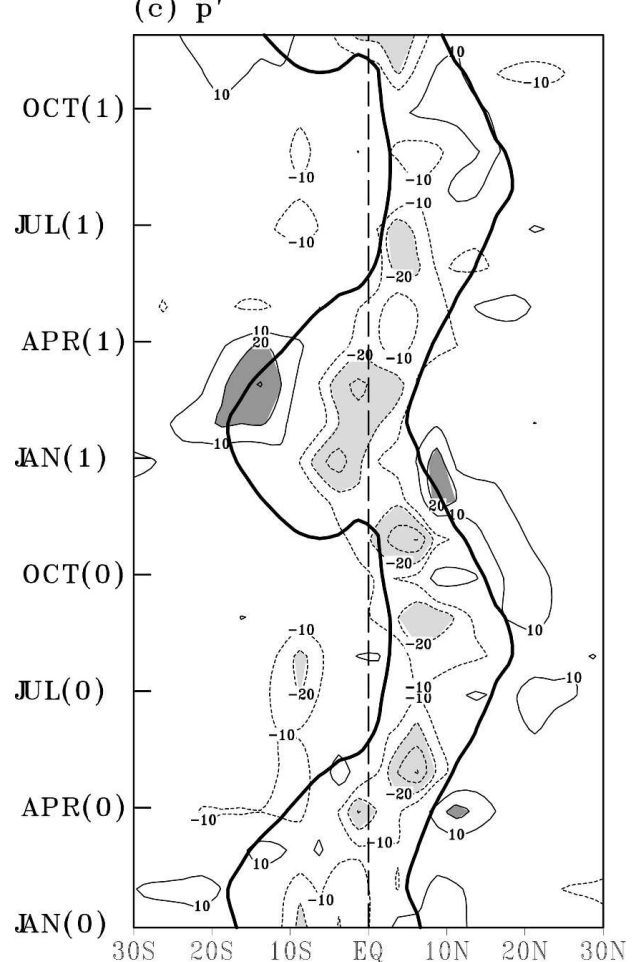

(b) $\mathrm{Ta}^{\prime}$

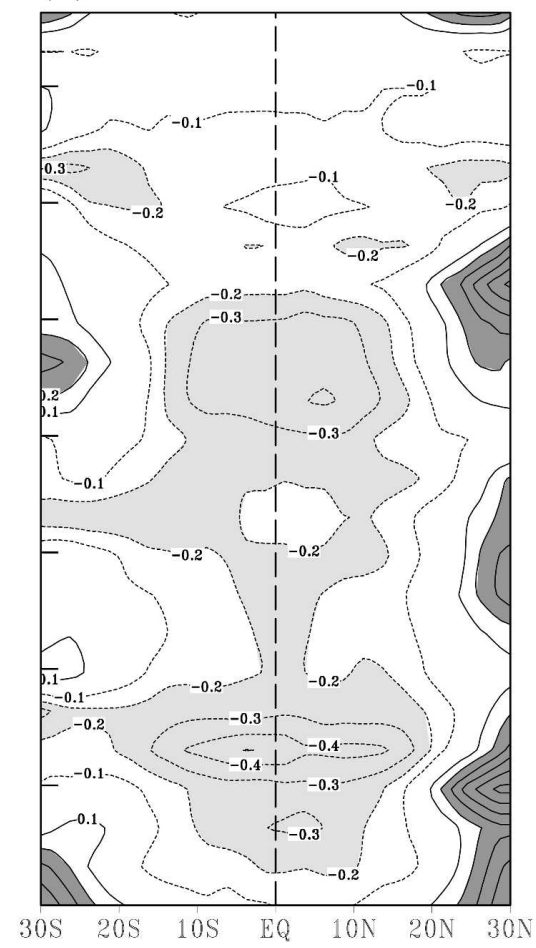

FIG. 3. Same as Fig. 2, but for the 19992000 La Niña, for (a) SST, (b) tropospheric temperature, and (c) precipitation anomalies. sign of the associated precipitation anomalies should also change. The main tropical precipitation anomalies, negative in this case, occur through the entire period with clear meridional movement (Fig. 3c), which sug- gests an association of the tropical precipitation anomalies with the seasonal movement of mean convection zone and the corresponding Hadley circulation. Weaker positive precipitation anomalies are also found 
over margins of convective regions, which are just north or south of the main negative anomalous precipitation band. Overall, the positive (negative) precipitation anomalies are over convective regions during an El Niño (La Niña) event, while the negative (positive) precipitation anomalies are found over margins of convective regions.

\section{Moisture and moist static energy budgets}

\section{a. Equations and derivation}

To understand the tropical precipitation anomalies induced by ENSO, we start with a vertically integrated moisture equation.

$$
\partial_{t}\langle q\rangle+\langle\mathbf{v} \cdot \nabla q\rangle+\left\langle\omega \partial_{p} q\right\rangle=\left\langle Q_{q}\right\rangle+E,
$$

where $E$ is evaporation, $\omega$ is pressure velocity, $\mathbf{v}$ is horizontal velocity, and the specific humidity $q$ is in energy units by absorbing the latent heat per unit mass $L$. Vertical integral \langle\rangle denotes a mass integration through the troposphere, with $p_{T}$ as the depth of the troposphere:

$$
\langle X\rangle=\frac{1}{g} \int_{p_{s}}^{p_{s}-p_{T}} X d p,
$$

where $g$ is gravity and $p_{s}$ is surface pressure. The moisture sink $\left\langle Q_{q}\right\rangle$ is related to precipitation $P$ by

$$
\left\langle Q_{q}\right\rangle=-P \text {. }
$$

The precipitation is in energy units of watts per square meter, which, divided by 28 , is millimeters per day. For time or ensemble averages, the time derivative term is negligible. Thus, the precipitation anomalies induced by ENSO can be written as

$$
\begin{aligned}
P^{\prime} \approx & -\left\langle\omega^{\prime} \partial_{p} \bar{q}\right\rangle-\left[\left\langle\bar{\omega} \partial_{p} q^{\prime}\right\rangle+\left(\left\langle\omega^{\prime} \partial_{p} q^{\prime}\right\rangle-\left\langle\overline{\omega^{\prime} \partial_{p} q^{\prime}}\right\rangle\right)\right] \\
& -\langle\mathbf{v} \cdot \nabla q\rangle^{\prime}+E^{\prime},
\end{aligned}
$$

where $\left(^{-}\right)$denotes climatology and ()$^{\prime}$ represents the departure from the climatology. The last term on the rhs of (4) is associated with local thermodynamic processes and the rest of the rhs terms of (4) are associated with dynamical processes. The interannual variation of the nonlinear effect $-\left(\left\langle\omega^{\prime} \partial_{p} q^{\prime}\right\rangle-\left\langle\overline{\omega^{\prime} \partial_{p} q^{\prime}}\right\rangle\right)$ and the effect of $-\left\langle\bar{\omega} \partial_{p} q^{\prime}\right\rangle$ are both associated with the vertical profile of moisture changes. Note that $\left\langle\overline{\omega^{\prime} \partial_{p} q^{\prime}}\right\rangle$ is the climatology of the nonlinear effect. The other nonlinear effect associated with the horizontal moisture transport is included in $-\langle\mathbf{v} \cdot \nabla q\rangle^{\prime}$. The nonlinear effects, such as $-\left(\left\langle\omega^{\prime} \partial_{p} q^{\prime}\right\rangle-\left\langle\overline{\omega^{\prime} \partial_{p} q^{\prime}}\right\rangle\right)$, include transients and changes to the basic state between ENSO and climatology.

In the Tropics, convection is the center of the dynamical processes. To estimate the anomalous vertical velocity $\omega^{\prime}$ associated with convection, a vertically integrated anomalous MSE equation is used here:

$$
\begin{aligned}
\left\langle\omega^{\prime} \partial_{p} \bar{h}\right\rangle \approx & -\left[\left\langle\bar{\omega} \partial_{p} h^{\prime}\right\rangle+\left(\left\langle\omega^{\prime} \partial_{p} h^{\prime}\right\rangle-\left\langle\overline{\omega^{\prime} \partial_{p} h^{\prime}}\right\rangle\right)\right] \\
& -\langle\mathbf{v} \cdot \nabla(q+T)\rangle^{\prime}+F^{\mathrm{net}^{\prime}},
\end{aligned}
$$

where $T$ is atmospheric temperature that absorbs the heat capacity at constant pressure $C_{p}$, and the MSE is $h=q+s$. The dry static energy is $s=T+\phi$, with $\phi$ as the geopotential. The net energy into the atmospheric column is

$$
F^{\text {net }}=F_{t}-F_{s} \text {. }
$$

The net heat flux at the top of the atmosphere (TOA) is

$$
F_{t}=S_{t}^{\downarrow}-S_{t}^{\uparrow}-R_{t}^{\uparrow},
$$

and the net heat flux at the surface is

$$
F_{s}=S_{s}^{\downarrow}-S_{s}^{\uparrow}+R_{s}^{\downarrow}-R_{s}^{\uparrow}-E-H .
$$

Subscripts $s$ and $t$ on the solar $\left(S^{\downarrow}\right.$ and $\left.S^{\uparrow}\right)$ and longwave $\left(R^{\uparrow}\right.$ and $\left.R^{\downarrow}\right)$ radiative terms denote surface and model top, respectively, and $H$ is sensible heat flux. Positive $F_{t}$ and $F_{s}$ indicate downward heat fluxes.

The term $\left\langle\omega \partial_{p} h\right\rangle$ can be divided into $\left\langle\omega \partial_{p} s\right\rangle$ and $\left\langle\omega \partial_{p} q\right\rangle$. The terms $\left\langle\omega \partial_{p} s\right\rangle$ and $\left\langle\omega \partial_{p} q\right\rangle$ show strong cancellation with each other, so $\left\langle\omega \partial_{p} h\right\rangle$ is a small difference between two large terms. The increase of the atmospheric boundary layer moisture modifies the static stability of convective regions, so convection and the associated precipitation are enhanced and $\left\langle\omega \partial_{p} q\right\rangle$ becomes more negative. The stronger convection can also increase convection height and then increase $\left\langle\omega \partial_{p} s\right\rangle$. Thus, $\left\langle\omega \partial_{p} s\right\rangle$ is highly sensitive to convection height, but $\left\langle\omega \partial_{p} q\right\rangle$ is not (Yu et al. 1998). Difficulty in estimating convection height from observations and climate model simulations creates the uncertainty of calculating $\left\langle\omega \partial_{p} s\right\rangle$. Overcoming the challenge of estimating convection height and $\left\langle\omega \partial_{p} s\right\rangle$ is an ongoing work. Here we neglect the contribution of $\left\langle\omega \partial_{p} s\right\rangle^{\prime}$ and focus only on $\left\langle\omega \partial_{p} q\right\rangle^{\prime}$. This is similar to the assumption of $\left\langle\omega \partial_{p} s\right\rangle^{\prime}=0$. In the current QTCM, $\left\langle\omega \partial_{p} s\right\rangle$ varies slightly only when convection is very deep, so $\left\langle\omega \partial_{p} s\right\rangle^{\prime} \approx 0$ (CN04). Neglecting the contribution of $\left\langle\omega \partial_{p} s\right\rangle$ cannot close the MSE budget, so the MSE budget analysis can only give us a first estimate on the effect for each term on the rhs of (5), not partitioning between each effect.

To interpret the budget analysis in observations, the QTCM simulations are also analyzed. In QTCM, under the QE closure, $\left\langle\omega \partial_{p} h\right\rangle$ is replaced by $M \nabla \cdot \mathbf{v}_{1}$, where $M$ is the gross moist stability and $\mathbf{v}_{1}$ is the baroclinic wind, which is a projection on the baroclinic structure associated with deep convection (Yu et al. 1998). The sign of $\boldsymbol{\nabla} \cdot \mathbf{v}_{1}$ is positive for lower-tropospheric convergence 
and upward motion. Defining a typical vertical velocity structure of deep convection $\Omega(p)$ gives $\omega \approx-\Omega(p) \boldsymbol{\nabla} \cdot \mathbf{v}_{1}$, so $M \equiv M_{s}-M_{q}$ with $M_{s}=-\left\langle\Omega \partial_{p} s\right\rangle$ and $M_{q}=\left\langle\Omega \partial_{p} q\right\rangle$. Thus, the anomalous moisture [(4)] and MSE [(5)] can be written as

$$
\begin{aligned}
P^{\prime}= & \bar{M}_{q} \boldsymbol{\nabla} \cdot \mathbf{v}_{1}^{\prime}+\left(M_{q}^{\prime} \boldsymbol{\nabla} \cdot \overline{\mathbf{v}}_{1}+M_{q}^{\prime} \boldsymbol{\nabla} \cdot \mathbf{v}_{1}^{\prime}\right) \\
& -(\mathbf{v} \cdot \boldsymbol{\nabla} q)^{\prime}+E^{\prime},
\end{aligned}
$$

and

$$
\begin{aligned}
\bar{M} \boldsymbol{\nabla} \cdot \mathbf{v}_{1}^{\prime}= & -\left(M^{\prime} \boldsymbol{\nabla} \cdot \overline{\mathbf{v}}_{1}+M^{\prime} \boldsymbol{\nabla} \cdot \mathbf{v}_{1}^{\prime}\right)-\langle\mathbf{v} \cdot \boldsymbol{\nabla}(T+q)\rangle^{\prime} \\
& +F_{t}^{\prime}-F_{s .}^{\prime} .
\end{aligned}
$$

The climatology of the nonlinear terms $M_{q}^{\prime} \boldsymbol{\nabla} \cdot \mathbf{v}_{1}^{\prime}$ and $M^{\prime} \boldsymbol{\nabla} \cdot \mathbf{v}_{1}^{\prime}$ are small in QTCM, so both $\overline{M_{q}^{\prime} \boldsymbol{\nabla} \cdot \mathbf{v}_{1}^{\prime}}$ and $\overline{M^{\prime} \boldsymbol{\nabla} \cdot \mathbf{v}_{1}^{\prime}}$ are neglected here. Using the anomalous MSE in (10) to replace the anomalous divergence associated with deep convection in the anomalous moisture in (9) yields

$$
\begin{aligned}
P^{\prime} \approx & \left(-\frac{\bar{M}_{q}}{\bar{M}} M^{\prime}+M_{q}^{\prime}\right) \nabla \cdot \overline{\mathbf{v}}_{1} \\
& +\left(-\frac{\bar{M}_{q}}{\bar{M}} M^{\prime}+M_{q}^{\prime}\right) \boldsymbol{\nabla} \cdot \mathbf{v}_{1}^{\prime} \\
& +\left(\frac{\bar{M}_{q}}{\bar{M}}+1\right)\left(-\langle\mathbf{v} \cdot \nabla q\rangle^{\prime}\right) \\
& +\frac{\bar{M}_{q}}{\bar{M}}\left(-\langle\mathbf{v} \cdot \boldsymbol{\nabla} T\rangle^{\prime}+F_{t}^{\prime}-F_{s}^{\prime}\right)+E^{\prime} .
\end{aligned}
$$

The factor $\bar{M}_{q} / \bar{M}$ is termed as the gross moist stability multiplier effect (Neelin and Su 2005). Estimating from observations with a theoretical formula, this factor is roughly 6 in the tropical convection zones ( $\mathrm{Yu}$ et al. 1998). Thus, the terms associated with $\bar{M}_{q} / \bar{M}$ are larger than those terms without this multiplier effect. For instance, $-\left(\bar{M}_{q} \bar{M}\right) M^{\prime}>M_{q}^{\prime}$, because $\bar{M}_{q} \bar{M}>1$. Because of the strong cancellation between $M_{s}^{\prime}$ and $M_{q}^{\prime}$, to accurately calculate $M^{\prime}$ is difficult. In the current QTCM, $M_{s}$ is assumed to be near constant, that is, $M_{s}^{\prime} \approx 0$, so $M^{\prime} \approx-M_{q}^{\prime}$. Therefore, $-M^{\prime} \nabla \cdot \overline{\mathbf{v}}_{1} \approx$ $M_{q}^{\prime} \boldsymbol{\nabla} \cdot \overline{\mathbf{v}}_{1}=-\left\langle\bar{\omega} \partial_{p} q^{\prime}\right\rangle$, which is the main source for inducing $M^{\prime}$, such as in CN04. Under this assumption, we only count the part of the $M^{\prime}$ effect associated with the low-level moisture change. This $M^{\prime}$ effect may be strongly modified when adding the effect of $M_{s}^{\prime}$, so interpreting the effect associated with $M^{\prime}$ obtained here must be approached with caution.

\section{b. Budget analysis}

In this study, we focused on variations in the meridional direction, so a zonal average is used throughout the analysis. Based on the equations discussed in the previous section, the NCEP2 is used to analyze the moisture and MSE budgets. In the moisture budget, $-\left\langle\omega^{\prime} \partial_{p} \bar{q}\right\rangle$ contributes more than $80 \%$ of the anomalous tropical precipitation, so $-\left\langle\omega^{\prime} \partial_{p} \bar{q}\right\rangle$, which is associated with the anomalous vertical motion, is the main source for inducing the tropical precipitation anomalies (Fig. 4). The spatial distribution of $-\left\langle\omega^{\prime} \partial_{p} \bar{q}\right\rangle$ is similar to the pattern of the precipitation anomalies shown in Fig. 2c. A dipole pattern of the anomalies with the positive in the south and the negative in the north appears around October of year 0 and ends around July of year 1 . The term $-\left\langle\omega^{\prime} \partial_{p} \bar{q}\right\rangle$ shows a clear meridional movement, similar to the seasonal variation of mean convection. In addition to $-\left\langle\omega^{\prime} \partial_{p} \bar{q}\right\rangle$, the sum of $-\left\langle\bar{\omega} \partial_{p} q^{\prime}\right\rangle$ and $-\left(\left\langle\omega^{\prime} \partial_{p} q^{\prime}\right\rangle-\overline{\left\langle\omega^{\prime} \partial_{p} q^{\prime}\right\rangle}\right)$ also shows a meridional movement for the positive anomalies (Fig. 4b). Both terms depend on the vertical distribution of moisture anomalies and have a similar pattern with a clear meridional movement, but $-\left(\left\langle\omega^{\prime} \partial_{p} q^{\prime}\right\rangle-\overline{\left\langle\omega^{\prime} \partial_{p} q^{\prime}\right\rangle}\right)$ is slightly larger than $-\left\langle\bar{\omega} \partial_{p} q^{\prime}\right\rangle$ (not shown). With positive low-level moisture anomalies shown in Fig. 2d, the mean upward motion of the Hadley circulation transports more moisture vertically, and then enhances the convection over the ascending branch.

The other two terms in (4), $-\langle\mathbf{v} \cdot \nabla q\rangle^{\prime}$ and $E^{\prime}$, do not show a clear meridional movement, such as in the precipitation anomalies (Fig. 2c), but they are definitely not symmetric to the equator. A strong negative $-\langle\mathbf{v} \cdot \nabla q\rangle^{\prime}$ is found near the equator from December of year 0 to May of year 1, with more to the north of the equator. The term $-\langle\mathbf{v} \cdot \nabla q\rangle^{\prime}$ includes the following three parts: $-\left\langle\overline{\mathbf{v}} \cdot \boldsymbol{\nabla} q^{\prime}\right\rangle,-\left\langle\mathbf{v}^{\prime} \cdot \boldsymbol{\nabla} \bar{q}\right\rangle$, and $-\left(\left\langle\mathbf{v}^{\prime} \nabla q^{\prime}\right\rangle-\left\langle\overline{\mathbf{v}^{\prime} \nabla q^{\prime}}\right\rangle\right)$. The nonlinear effect of $-\left(\left\langle\mathbf{v}^{\prime} \nabla q^{\prime}\right\rangle-\left\langle\overline{\mathbf{v}^{\prime} \nabla q^{\prime}}\right\rangle\right)$ contributes to most of the negative anomalies of $-\langle\mathbf{v} \cdot \nabla q\rangle^{\prime}$. The rest of the terms, $-\left\langle\overline{\mathbf{v}} \cdot \nabla q^{\prime}\right\rangle$ and $-\left\langle\mathbf{v}^{\prime} \cdot \nabla \bar{q}\right\rangle$, are also negative over the Northern Hemisphere, but their amplitudes are relatively smaller (not shown). Positive $E^{\prime}$ is found over the Northern Hemisphere, a region that is also dominated by negative $-\langle\mathbf{v} \cdot \nabla q\rangle^{\prime}$ (Figs. $4 \mathrm{c}$ and $4 \mathrm{~d}$ ). This implies a strong cancellation between $-\langle\mathbf{v} \cdot \nabla q\rangle^{\prime}$ and $E^{\prime}$ over the equatorial region. In addition to the positive $E^{\prime}$ discussed above, negative $E^{\prime}$ also occurs over the Southern Hemisphere from December of year 0 to May of year 1. This distribution of $E^{\prime}$ tends to cool the ocean over the Northern Hemisphere and warm the ocean over the Southern Hemisphere. That may be the reason why the positive SST anomalies extend less poleward over the Northern Hemisphere than over the Southern Hemisphere (Fig. 2a).

The moisture budget analysis shows that $-\left\langle\omega^{\prime} \partial_{p} \bar{q}\right\rangle$, which is associated with $\omega^{\prime}$, is the most important con- 
(a) -wadqm (NCEP2)

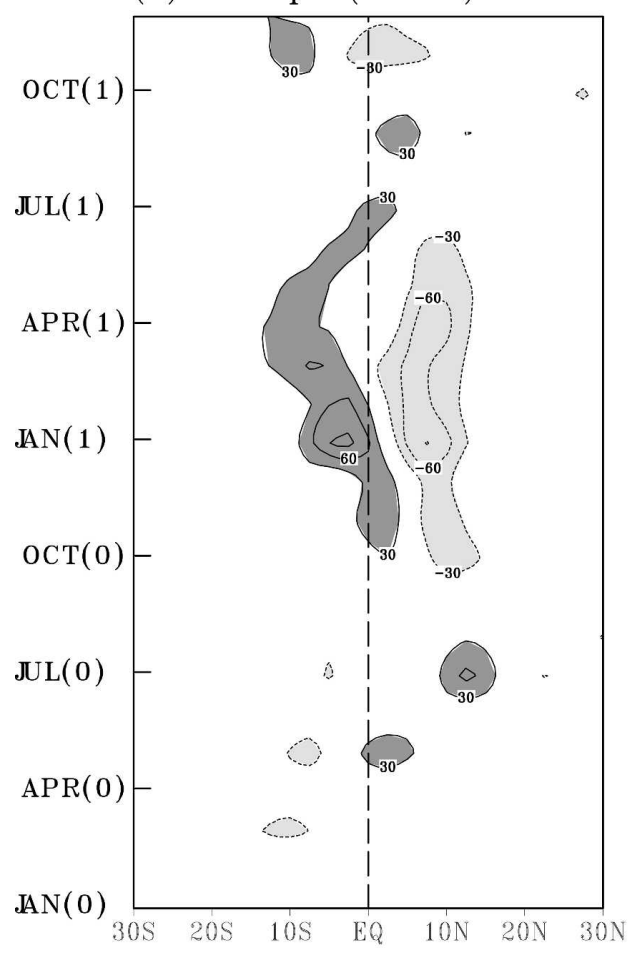

(b) -wmdqa-wadqa
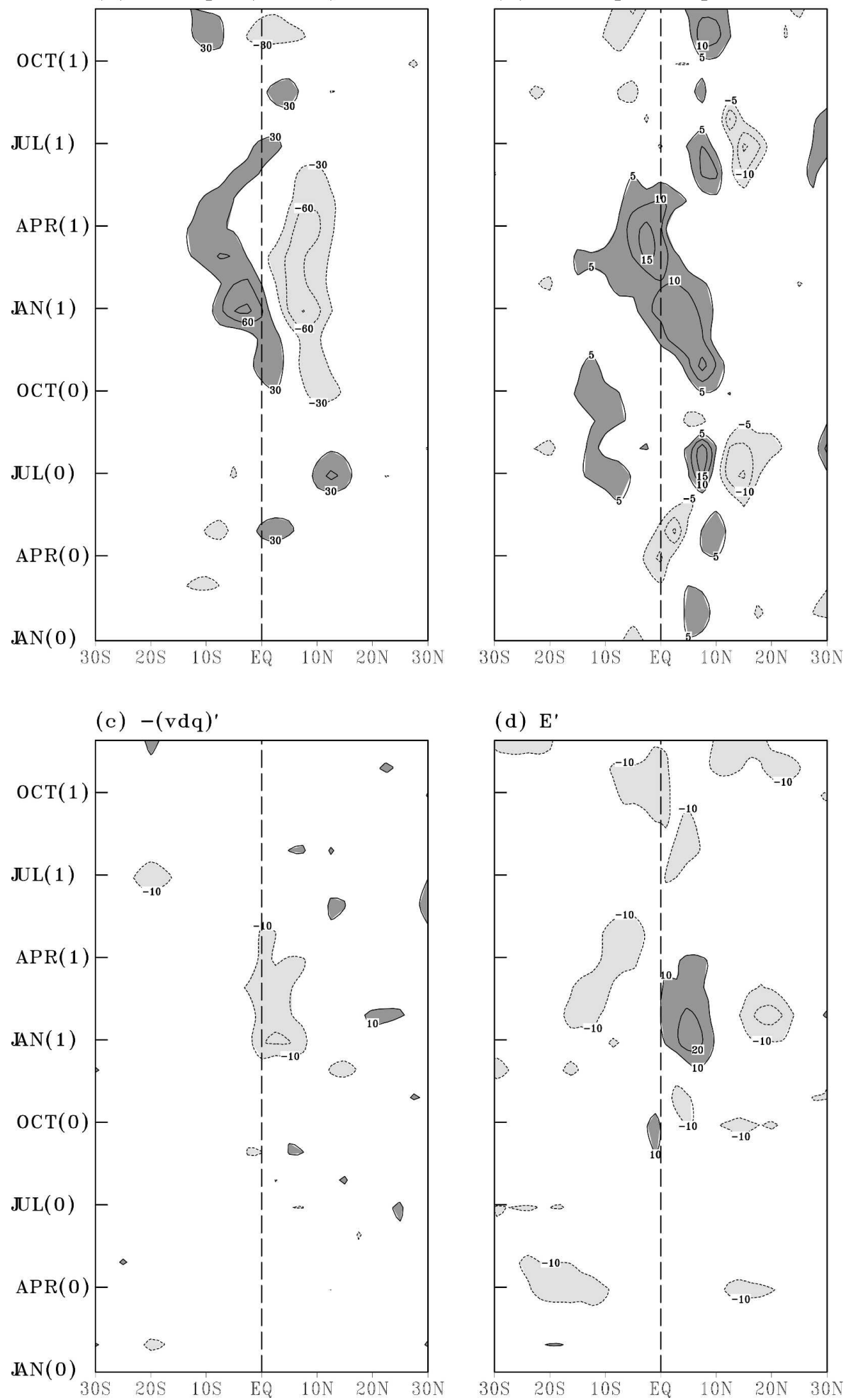

(d) $E^{\prime}$

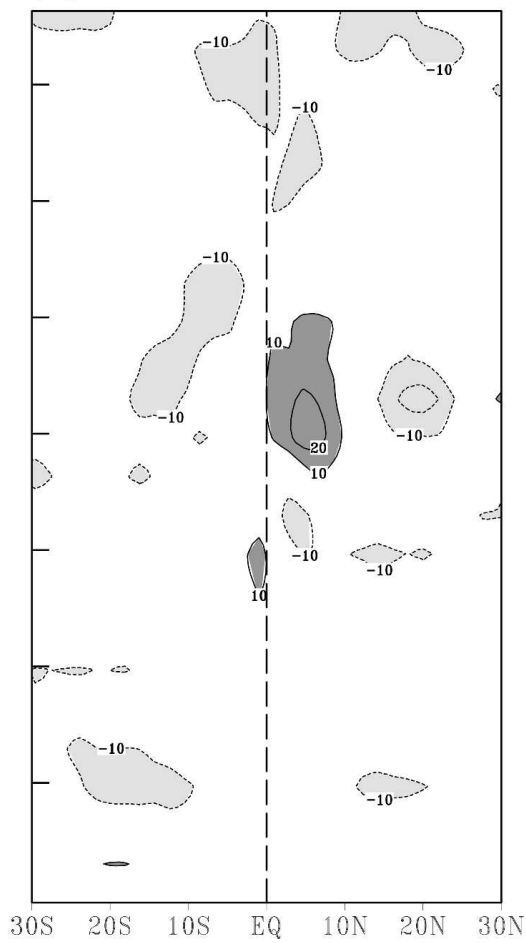

FIG. 4. Same as Fig. 2, but for the terms in the moisture budget [(4)]: (a) $-\left\langle\omega^{\prime} \partial_{p} \bar{q}\right\rangle$, (b) $-\left[\left\langle\bar{\omega} \partial_{p} q^{\prime}\right\rangle+\right.$ $\left(\left\langle\omega^{\prime} \partial_{p} q^{\prime}\right\rangle-\left\langle\overline{\left.\omega^{\prime} \partial_{p} q^{\prime}\right\rangle}\right)\right]$, (c) $-\langle\mathbf{v} \cdot \nabla q\rangle^{\prime}$, and (d) $E^{\prime}$. The vertical integral is from 1000 to $200 \mathrm{hPa}$. 
(a) Fs' (NCEP2)

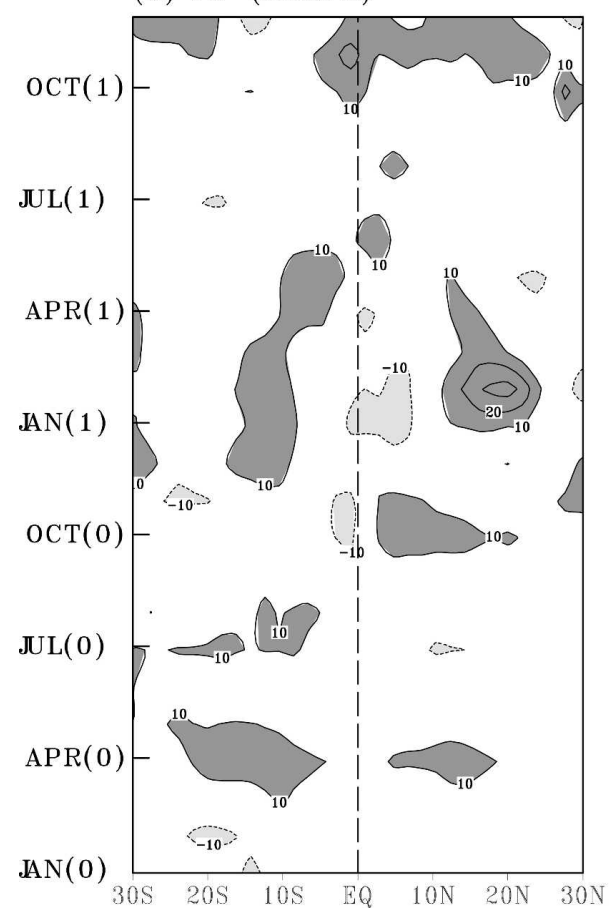

(b) $-(\mathrm{vdT}+\mathrm{vdq})^{\prime}$

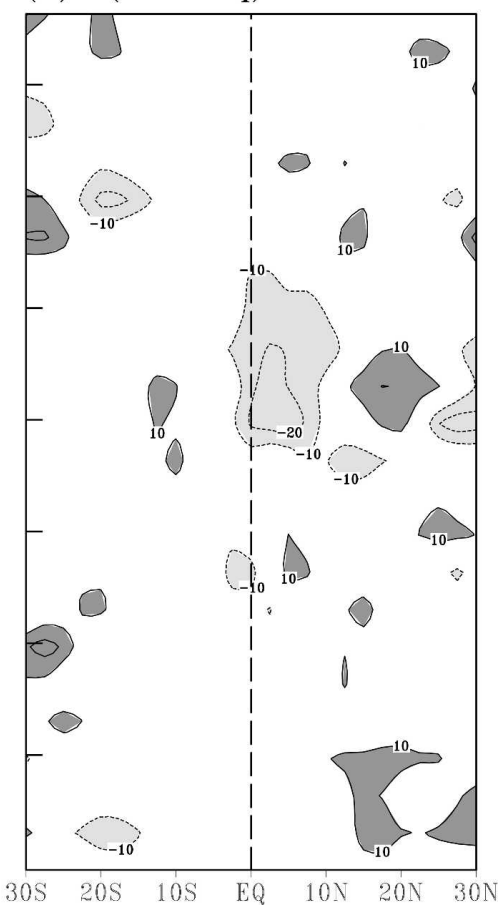

FIG. 5. Same as Fig. 2, but for the terms in the MSE budget (5): (a) $F_{s}^{\prime}$ and (b) $-\langle\mathbf{v} \cdot \nabla(T+q)\rangle^{\prime}$.

tribution to the precipitation anomalies (Fig. 2). To estimate $\omega^{\prime}$, we use the MSE of (5) to examine possible contributions to the anomalous vertical motion. In El Niño, the warm SST anomalies over the eastern Pacific has a major contribution to the MSE budget via the net surface heat flux $F_{s}^{\prime}$. The net TOA heat flux anomalies $F_{t}^{\prime}$ are associated with a cloud radiative feedback, and they are relatively small compared with $F_{s}^{\prime}$ because of the strong cancellation between cloud longwave and shortwave radiation in the Tropics (Kiehl 1994; Ramanathan et al. 1989). Thus, the net energy into the atmosphere, $F^{\text {net' }}=F_{t}^{\prime}-F_{s}^{\prime}$, can be estimated by $F_{s}^{\prime}$. Figure 5a does show a warming effect on the atmosphere along the equator, that is, $-F_{s}^{\prime}>0$, and this warming is roughly symmetric to the equator. However, the upward (negative) $F_{s}^{\prime}$ near the equator is much smaller than what would be expected from the SST anomalies shown in Fig. 2a. This discrepancy between the SST anomalies and $F_{s}^{\prime}$ is due to a much weaker surface cloud radiative effect in the NCEP2 data. Examining other data, such as from the 40-yr European Centre for Medium-Range Weather Forecasts (ECMWF) Re-Analysis (ERA-40; Uppala et al. 2005), negative $F_{s}^{\prime}$ is much stronger and is also symmetric to the equator (not shown). Thus, the symmetric $F_{s}^{\prime}$ cannot directly induce the asymmetry of the tropical precipitation anomalies. Moreover, $F_{s}^{\prime}$ and the net energy into the atmosphere $F^{\text {net' }}$ is also not physically consistent with the anomalous vertical motion represented by $-\left\langle\omega^{\prime} \partial_{p} \bar{q}\right\rangle$. The effect of $F_{s}^{\prime}$ warms the atmosphere over the tropical Northern Hemisphere, that is, $F_{s}^{\prime}<0$, where the anomalous vertical motion is downward (Fig. $6)$, so $F_{s}^{\prime}$ does not directly force the hemispherical asymmetry of the tropical precipitation anomalies. In fact, $F_{s}^{\prime}$ is opposing the change of the tropical precipitation over the Northern Hemisphere shown in Fig. 2a, even though tropical precipitation anomalies are believed to be initiated by warm SST anomalies over the equatorial eastern Pacific via $F_{s}^{\prime}$.

On the other hand, the sum of $-\left\langle\bar{\omega} \partial_{p} q^{\prime}\right\rangle$ and $-\left(\left\langle\omega^{\prime} \partial_{p} q^{\prime}\right\rangle-\overline{\left\langle\omega^{\prime} \partial_{p} q^{\prime}\right\rangle}\right)$, a part of $-\left[\left\langle\bar{\omega} \partial_{p} h^{\prime}\right\rangle+\left(\left\langle\omega^{\prime} \partial_{p} h^{\prime}\right\rangle-\right.\right.$ $\left.\left.\overline{\left\langle\omega^{\prime} \partial_{p} h^{\prime}\right\rangle}\right)\right]$, which is associated with $M^{\prime}$, shows a very clear meridional movement, especially for the positive anomalies. This meridional movement is associated with the seasonal variation of the ascending branch of the Hadley circulation and the nonlinear effect of the vertical moisture transport. Thus, both $-\left\langle\bar{\omega} \partial_{p} q^{\prime}\right\rangle$ and $-\left(\left\langle\omega^{\prime} \partial_{p} q^{\prime}\right\rangle-\overline{\left\langle\omega^{\prime} \partial_{p} q^{\prime}\right\rangle}\right)$ play a major role in inducing first the anomalous upward motion and then the associated positive precipitation anomalies. Note that $-\left\langle\bar{\omega} \partial_{p} q^{\prime}\right\rangle$ and $-\left(\left\langle\omega^{\prime} \partial_{p} q^{\prime}\right\rangle-\overline{\left\langle\omega^{\prime} \partial_{p} q^{\prime}\right\rangle}\right)$ can also directly affect the tropical precipitation via the moisture budget, but with less contribution than the dynamical feedback discussed here. 
$\mathrm{FMA}(1) \mathrm{wm}$ and $\mathrm{w}^{\prime}$

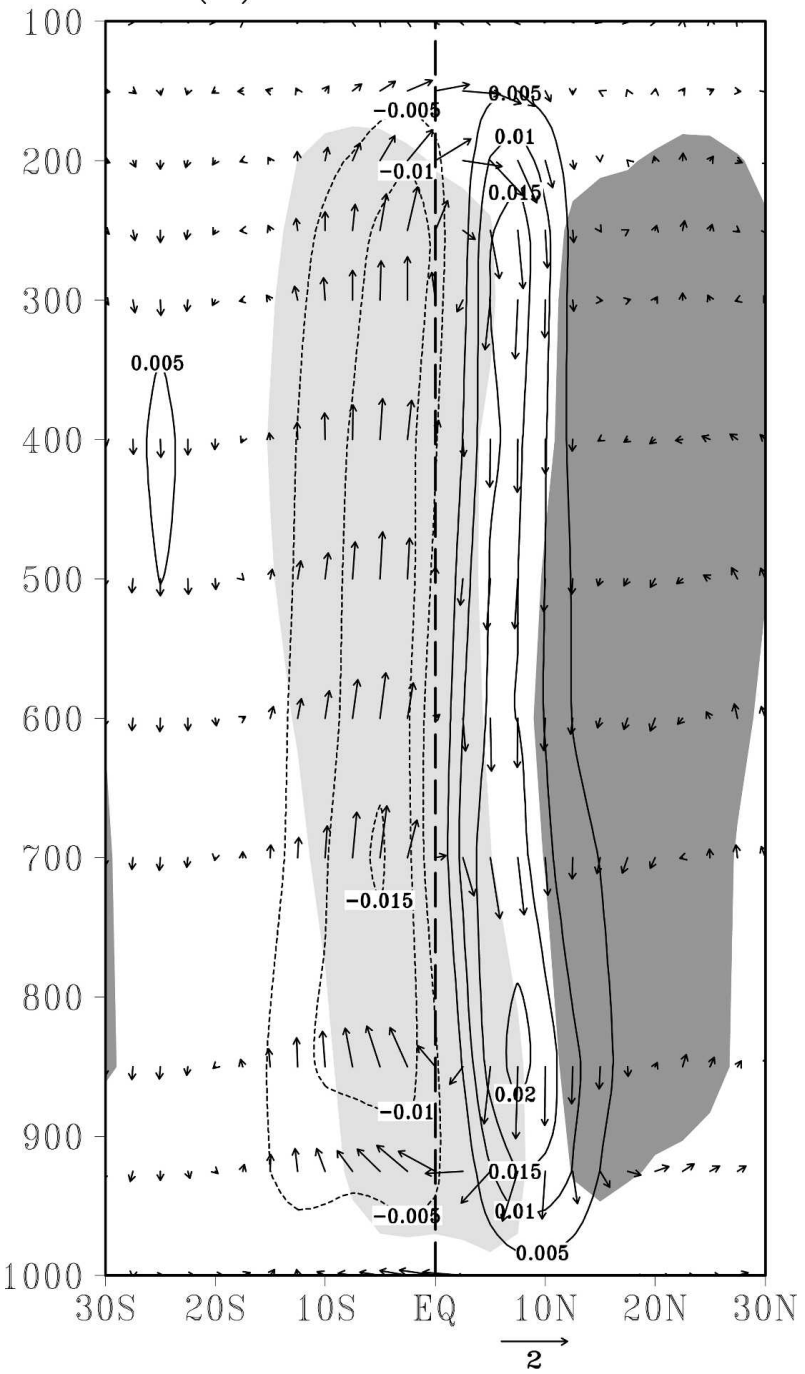

FIG. 6. The zonally averaged mean pressure velocity $\bar{\omega}$ (shading) and the anomalous pressure velocity $\omega^{\prime}$ (contours) in FMA from NCEP2. The light shading is for upward motion and the dark shading is downward motion. The vectors are anomalous winds for meridional component $v^{\prime}$ and $\omega^{\prime} \times 100$.

Another important term in the MSE budget is $-\langle\mathbf{v} \cdot \boldsymbol{\nabla}(T+q)\rangle^{\prime}$, the horizontal MSE transport. Figure $5 \mathrm{~b}$ shows that maximum negative $-\langle\mathbf{v} \cdot \boldsymbol{\nabla}(T+q)\rangle^{\prime}$ is found near the equator from December of year 0 to May of year 1, but most negative anomalies are over the Northern Hemisphere, where the precipitation anomalies are also negative. This indicates that $-\langle\mathbf{v} \cdot \nabla(T+q)\rangle^{\prime}$ is a possible source of the tropical precipitation reduction shown in Fig. 2c via the dynamical feedback associated with $\omega^{\prime}$. The distribution of $-\langle\mathbf{v} \cdot \nabla(T+q)\rangle^{\prime}$ does not show any sign of a meridional movement, but it coincides well with the maximum negative $-\left\langle\omega^{\prime} \partial_{p} \bar{q}\right\rangle$ shown in Fig. 4a. In $-\langle\mathbf{v} \cdot \nabla(T+q)\rangle^{\prime},-\langle\mathbf{v} \cdot \nabla q\rangle^{\prime}$ is the domi- nant term, while $-\langle\mathbf{v} \cdot \nabla T\rangle^{\prime}$ just enhances the anomalies without changing the pattern of $-\langle\mathbf{v} \cdot \nabla(T+q)\rangle^{\prime}$ (Figs. $4 \mathrm{c}$ and $5 \mathrm{c})$.

\section{c. Mechanisms}

From the moisture budget analysis in the observations, the asymmetry of the tropical precipitation anomalies associated with ENSO is mainly determined by dynamical feedbacks via $-\left\langle\omega^{\prime} \partial_{p} \bar{q}\right\rangle$, which is associated with $\omega^{\prime}$. In the analysis of the MSE budget, $\omega^{\prime}$ is affected by $-\left\langle\bar{\omega} \partial_{p} q^{\prime}\right\rangle,-\left(\left\langle\omega^{\prime} \partial_{p} q^{\prime}\right\rangle-\left\langle\overline{\left.\omega^{\prime} \partial_{p} q^{\prime}\right\rangle}\right)\right.$ and $-\langle\mathbf{v} \cdot \boldsymbol{\nabla}(T+q)\rangle^{\prime}$, and those terms are associated with the Hadley circulation. We thus examine the Hadley circulation in February-April (FMA) when the precipitation asymmetry is a maximum (Fig. 6). The anomalous upward motion is found over the Southern Hemisphere where the ascending branch of the Hadley circulation is located. The anomalous downward motion is found over the Northern Hemisphere where the northern margin of the ascending branch of the Hadley circulation is, and is dominated by the low-level northerly winds associated with the Hadley circulation. Thus, the ascending branch of the Hadley circulation is enhanced and the descending branch shifts southward slightly.

During El Niño, the effect of $-\left\langle\bar{\omega} \partial_{p} q^{\prime}\right\rangle$ is associated with an increase of low-level moisture, which is enhanced by the warm SST anomalies via local processes (such as evaporation), and the warm tropospheric temperature anomalies via the moist convective process over convective regions (NCS03; CN04). The SST anomalies show a meridional gradient with warm anomalies near the equator and cold anomalies at higher latitudes. These SST anomalies create a meridional gradient of the moisture anomalies. The process associated with warm tropospheric temperature anomalies also creates the meridional gradient of the moisture anomalies between convective and nonconvective regions. The higher low-level moisture over convective regions reduces gross moist stability $M(\mathrm{Yu}$ et al. 1998) and destabilizes the atmosphere, so convection and the associated precipitation are enhanced. This effect is termed the anomalous gross moist stability $\left(M^{\prime}\right)$ mechanism or the "rich-get-richer mechanism", which was first proposed by CN04 in a global warming study. The maximum $-\left\langle\bar{\omega} \partial_{p} q^{\prime}\right\rangle$ follows the seasonal variation of the mean tropical convection $\bar{\omega}$, so the associated precipitation anomalies should always be over the summer hemisphere. The other effect associated with the nonlinear term $-\left(\left\langle\omega^{\prime} \partial_{p} q^{\prime}\right\rangle-\overline{\left\langle\omega^{\prime} \partial_{p} q^{\prime}\right\rangle}\right)$ also induces positive tropical precipitation anomalies and has the similar pattern of $-\left\langle\bar{\omega} \partial_{p} q^{\prime}\right\rangle$, following the seasonal movement of mean convection. This nonlinear effect is associated with vertical moisture transport and includes 
contributions from transients and a change in basic state from seasonal climatology to El Niño. Both effects of $-\left\langle\bar{\omega} \partial_{p} q^{\prime}\right\rangle$ and $-\left(\left\langle\omega^{\prime} \partial_{p} q^{\prime}\right\rangle-\overline{\left\langle\omega^{\prime} \partial_{p} q^{\prime}\right\rangle}\right)$ enhance convection over the ascending branch of the Hadley circulation, so the Hadley circulation is enhanced (Fig. 6). The low-level moisture over the descending area is then reduced by stronger subsidence (Fig. 6) and the meridional gradient of the moisture anomalies are further enhanced.

The effect of the horizontal MSE transport $-\langle\mathbf{v} \cdot \nabla(T+$ $q)\rangle^{\prime}$ can be divided into the following three terms: $-\left\langle\overline{\mathbf{v}} \cdot \boldsymbol{\nabla}(T+q)^{\prime}\right\rangle,-\left\langle\mathbf{v}^{\prime} \cdot \nabla \overline{(T+q)}\right\rangle$, and $-\left(\left\langle\mathbf{v}^{\prime} \cdot \nabla(T+\right.\right.$ $\left.\left.q)^{\prime}\right\rangle-\left\langle\overline{\mathbf{v}^{\prime} \cdot \nabla(T+q)^{\prime}}\right\rangle\right)$. The first term is associated with the upped-ante mechanism (NCS03; CN04), the second term is associated with the anomalous wind mechanism (Neelin and Su 2005), and the last term is the nonlinear effect associated with the horizontal MSE transport. In the upped-ante mechanism, the precipitation over the tropical Northern Hemisphere, where there are margins of the ITCZ, is reduced during El Niño by the import of dry and cold air from nonconvective regions that is associated with the northerly winds of the mean Hadley circulation (Fig. 6) on the background of the anomalous moisture gradient between the ascending and descending areas (Fig. 2d). In the anomalous wind mechanism, the anomalous northerly winds induced by El Niño transport dry and cold air from the convective region to the convective center (Fig. 6), which is consistent with the finding of $\mathrm{Su}$ and Neelin (2002). The nonlinear effect of $\left.-\left(\left\langle\mathbf{v}^{\prime} \cdot \nabla(T+q)^{\prime}\right\rangle-\overline{\left\langle\mathbf{v}^{\prime} \cdot \nabla(T+q)^{\prime}\right.}\right\rangle\right)$ also reduces the tropical precipitation just north of the equator (not shown). In other words, all three effects associated with $-\langle\mathbf{v} \cdot \nabla(T+q)\rangle^{\prime}$ tend to induce negative precipitation anomalies over the tropical Northern Hemisphere.

To further investigate those effects associated with $M^{\prime}$ and the effect of the horizontal MSE transport in the hemispherical asymmetry of the tropical precipitation anomalies, experiments using QTCM are analyzed. The zonal average of the precipitation anomalies in the STND experiments are shown in Fig. 7a. The positive precipitation anomalies do not migrate as far poleward as in the observation (Fig. 2c); this might be due to a relatively narrower migration range of the mean convection zone in QTCM. However, the positive precipitation anomalies do roughly follow the mean tropical convection and move meridionally (the thick line). During the peak phase of the 1982/83 El Niño, positive precipitation anomalies are over the Southern (summer) Hemisphere, while negative precipitation anomalies are also found over the Northern (winter) Hemisphere. This distribution is similar to the pattern of $\bar{M} \boldsymbol{\nabla} \cdot \mathbf{v}_{1}^{\prime}$ (Fig. 8a), which is equivalent to $-\left\langle\omega^{\prime} \partial_{p} \bar{h}\right\rangle$, so the term $\bar{M} \boldsymbol{\nabla} \cdot \mathbf{v}_{1}^{\prime}$ is the main source for tropical precipitation anomalies. Analyzing the MSE budget of the STND experiments, $-\left(M^{\prime} \boldsymbol{\nabla} \cdot \overline{\mathbf{v}}_{1}+M^{\prime} \boldsymbol{\nabla} \cdot \mathbf{v}_{1}^{\prime}\right)$ and $-\langle\mathbf{v} \cdot \nabla(T+q)\rangle^{\prime}$ show clear asymmetric patterns between two sides of the equator (Figs. $8 \mathrm{~b}$ and $8 \mathrm{c}$ ). The term $-M^{\prime} \nabla \cdot \overline{\mathbf{v}}_{1}$, equivalent to $-\left\langle\bar{\omega} \partial_{p} h^{\prime}\right\rangle$ or $-\left\langle\bar{\omega} \partial_{p} q^{\prime}\right\rangle$ in this study, is associated with the rich-get-richer mechanism, and $-M^{\prime} \boldsymbol{\nabla} \cdot \mathbf{v}_{1}^{\prime}$ is associated with the nonlinear effect of the vertical moisture transport. Both effects of $-M^{\prime} \boldsymbol{\nabla} \cdot \overline{\mathbf{v}}_{1}$ and $-M^{\prime} \boldsymbol{\nabla} \cdot \mathbf{v}_{1}^{\prime}$ contribute to positive precipitation anomalies over convective regions, but their amplitude is much weaker than what the observation implies in Fig. 4b. As discussed in CN04 and Chou et al. (2006), uncertainties in $M^{\prime}$ create errors in calculating the effect associated with $M^{\prime}$, so the amplitude of the terms associated with $\mathrm{M}^{\prime}$ is relatively weak in the QTCM simulations (Fig. 8). However, Fig. 8b implies that the $M^{\prime}$ effect does play a role in determining the positive anomalies of the asymmetry. The effect of $-\langle\mathbf{v} \cdot \boldsymbol{\nabla}(T+q)\rangle^{\prime}$ not only contributes to the negative precipitation anomalies over the northern margins of ITCZ, but also contributes slightly to the positive precipitation anomalies over the convective regions; this is a little different from the observations discussed above. In the observations, stronger noise may weaken the signal of the impacts of $-\langle\mathbf{v} \cdot \boldsymbol{\nabla}(T+q)\rangle^{\prime}$ on the positive precipitation anomalies over convective regions. In the STND experiments, the contribution of $F_{s}^{\prime}$, which is associated with the warm SST anomalies over the equatorial eastern Pacific, is relatively stronger than the observed $F_{s}^{\prime}$ shown in Fig. 5a, but is similar to $F_{s}^{\prime}$ obtained from the ERA-40 data and shows a symmetric distribution to the equator. Thus, $F_{s}^{\prime}$ cannot directly induce the asymmetry of the tropical precipitation anomalies. Overall, the asymmetry of the tropical precipitation anomalies in the STND experiments is attributed to the effects of $-\left(M^{\prime} \boldsymbol{\nabla} \cdot \overline{\mathbf{v}}_{1}+M^{\prime} \boldsymbol{\nabla} \cdot \mathbf{v}_{1}^{\prime}\right)$ and $-\langle\mathbf{v} \cdot \boldsymbol{\nabla}(T+q)\rangle^{\prime}$, similar to the analysis of the observation, but the tendency of the asymmetry is weaker than the observation, resulting from stronger $F_{s}^{\prime}$ and weaker $-\left(M^{\prime} \boldsymbol{\nabla} \cdot \overline{\mathbf{v}}_{1}+\right.$ $\left.M^{\prime} \boldsymbol{\nabla} \cdot \mathbf{v}_{1}^{\prime}\right)$. A sensitivity test with prescribed symmetric SST anomalies is also performed and the precipitation asymmetry still exists, but with a more narrow range of the meridional movement (not shown). This implies that the precipitation asymmetry can be induced without the weak asymmetric SST anomalies shown in Fig. 2a.

To further examine the effect associated with $M^{\prime}$ and the effect of $-\langle\mathbf{v} \cdot \nabla(T+q)\rangle^{\prime}$, two pairs of experiments - fixed $M$ and fixed advtq—are performed. The fixed- $M$ experiments set the anomalous gross moist stability $M^{\prime}$ to zero, so the effect associated with $M^{\prime}$ is not found in these experiments. Figure $7 \mathrm{~b}$ shows the pre- 
(a) $\mathrm{p}^{\prime}$

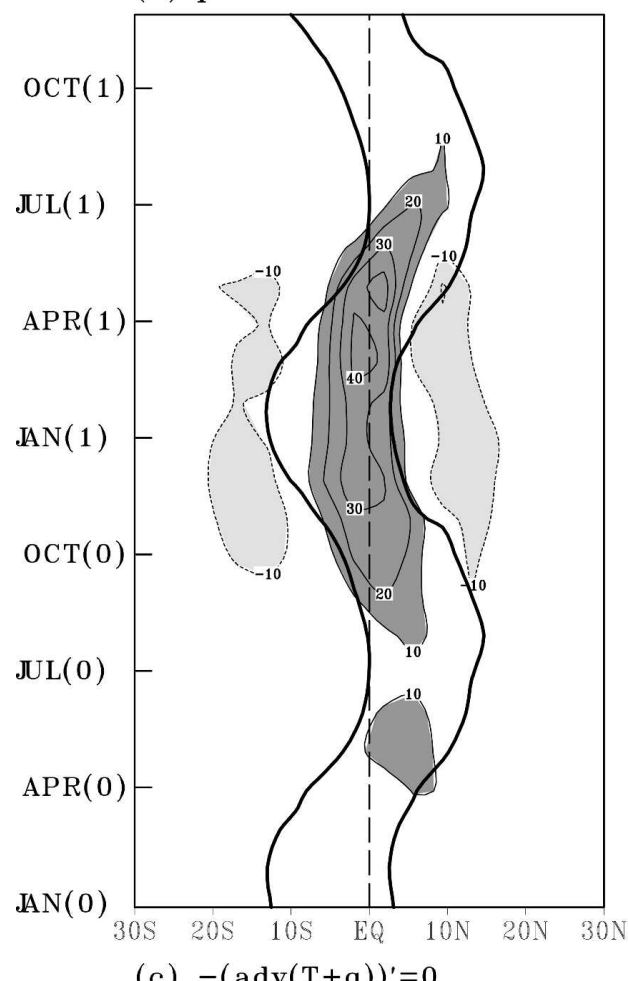

(c) $-(\operatorname{adv}(\mathrm{T}+\mathrm{q}))^{\prime}=0$

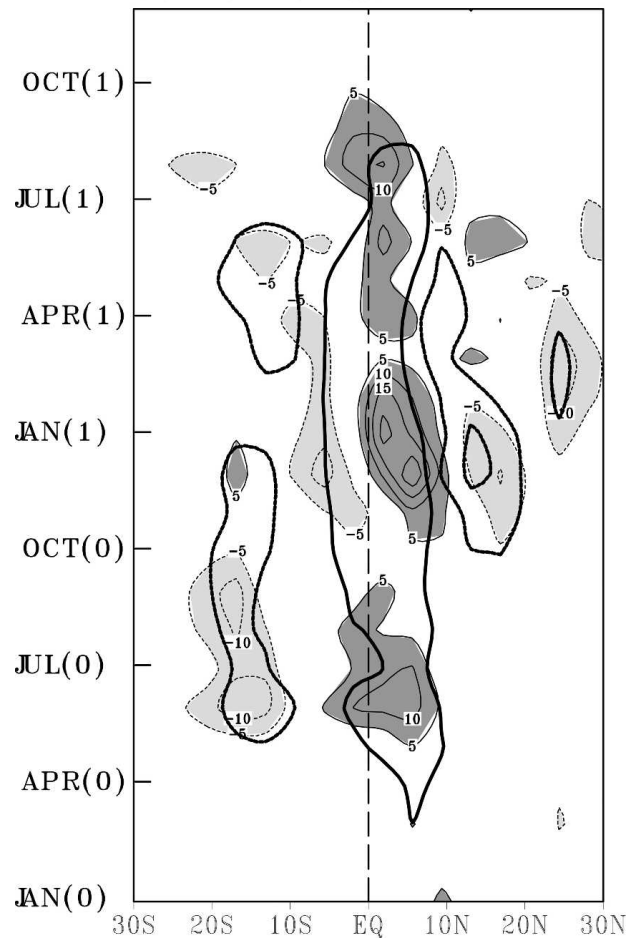

(b) $\mathrm{Ma}=0$

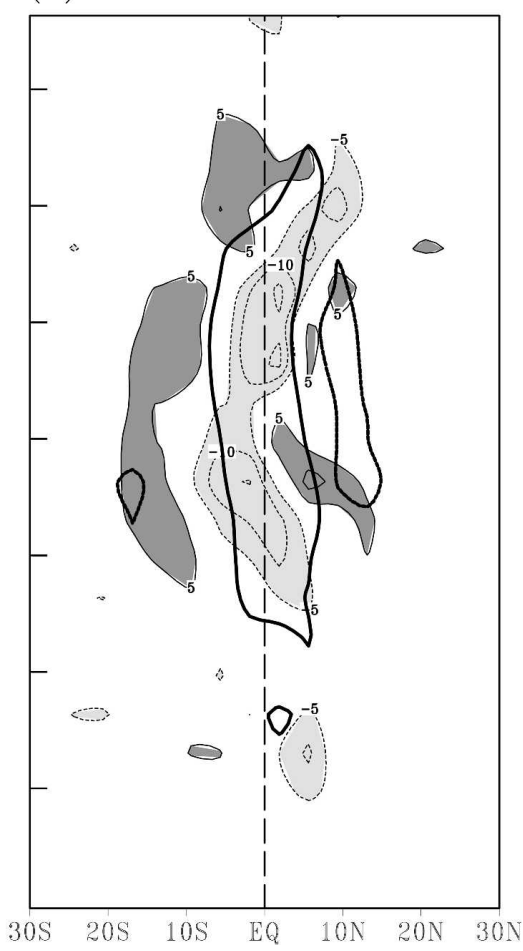

FIG. 7. The precipitation anomalies of the QTCM experiments for the (a) STND, (b) fixed- $M$ minus STND, and (c) fixedadvtq minus STND runs. See text for the experiment description. The thick line in (a) is the $120 \mathrm{~W} \mathrm{~m}^{-2}$ contour of precipitation climatology. The thick line in (b) and (c) is the $\pm 10 \mathrm{~W} \mathrm{~m}^{-2}$ contour of precipitation anomalies for the fixed- $M$ runs and the fixed-advtq runs, respectively. cipitation differences of the fixed- $M$ minus STND experiments. A clear reduction of the tropical precipitation anomalies is found over convective regions, particularly for the positive anomalies, when the effects associated with $M^{\prime}$ are suppressed. Thus, the effect associated with $M^{\prime}$ is responsible for most of the seasonal movement of the positive precipitation anomalies. The second pair of experiments is the fixed-advtq experi- 

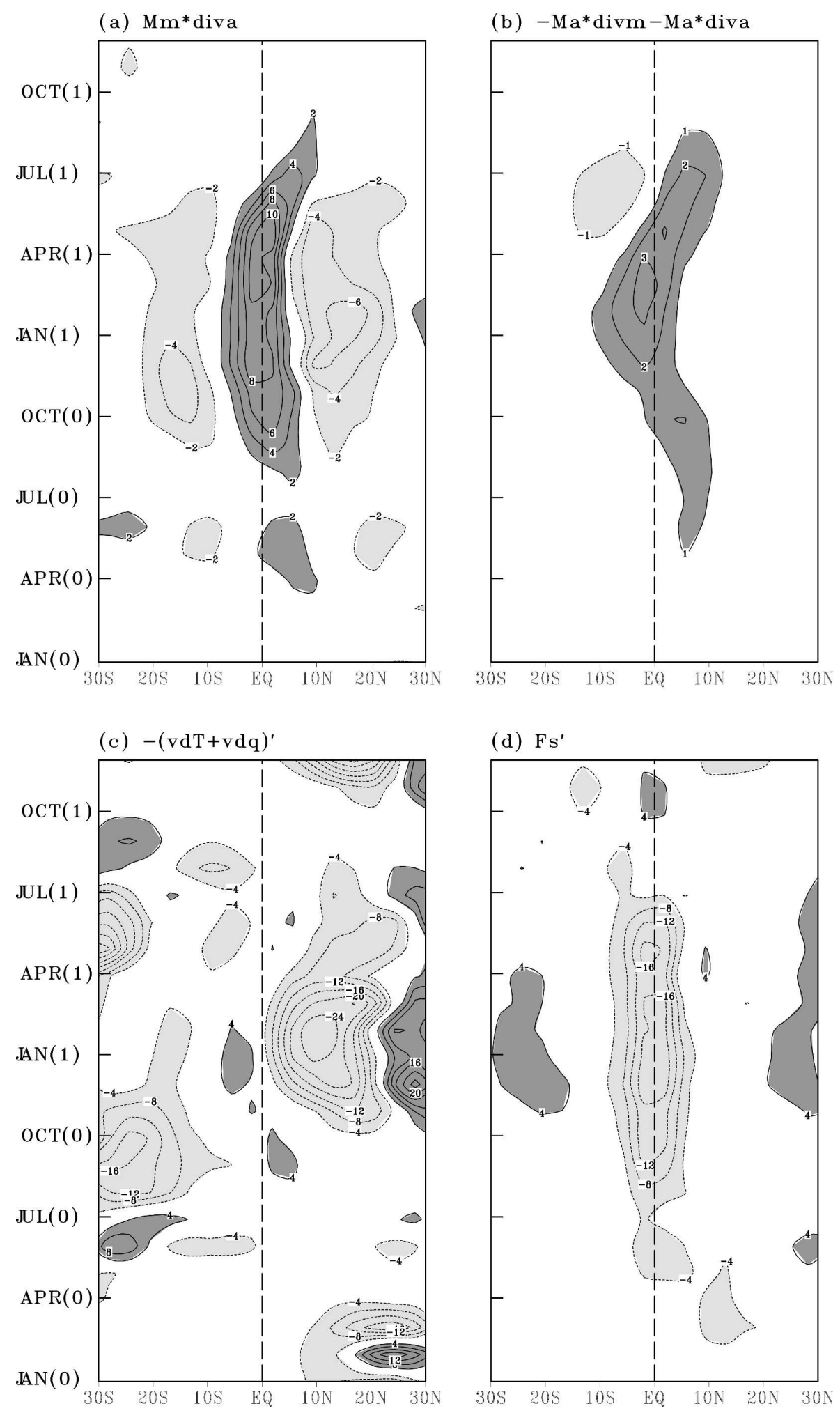

(d) $\mathrm{Fs}^{\prime}$

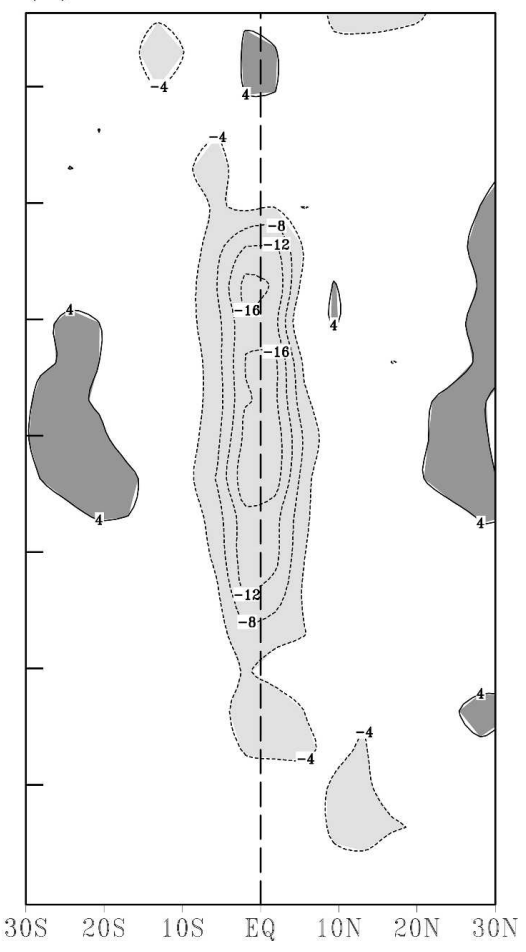

FIG. 8. The MSE budget of the QTCM STND experiments: (a) $\bar{M} \boldsymbol{\nabla} \cdot \mathbf{v}_{1}^{\prime}$, (b) $-\left(M^{\prime} \boldsymbol{\nabla} \cdot \overline{\mathbf{v}}_{1}+M^{\prime} \boldsymbol{\nabla} \cdot \mathbf{v}_{1}^{\prime}\right),\left(\right.$ c) $-\langle\mathbf{v} \cdot \boldsymbol{\nabla}(T+q)\rangle^{\prime}$, and (d) $F_{s}^{\prime}$. 
ments, which suppress the horizontal advection of MSE, that is, $-\langle\mathbf{v} \cdot \boldsymbol{\nabla}(T+q)\rangle^{\prime}=0$. The precipitation differences of the fixed-advtq minus STND experiments indicate that both negative precipitation anomalies over the Northern Hemisphere and positive precipitation anomalies over the Southern Hemisphere are weakened, with an emphasis on the negative precipitation anomalies (Fig. 7c). Thus, the effect of the horizontal MSE transport does reduce the tropical precipitation anomalies over the Northern Hemisphere and slightly decreases the tropical precipitation anomalies over the Southern Hemisphere.

Based on (11), the precipitation anomalies are determined mainly by the effects associated with $M^{\prime}$, the effect of $-\langle\mathbf{v} \cdot \nabla q\rangle^{\prime}$ (or $\left.-\langle\mathbf{v} \cdot \boldsymbol{\nabla}(T+q)\rangle^{\prime}\right)$ and $F_{s}^{\prime}$. Other terms, such as $M_{q}^{\prime}, F_{t}^{\prime}$, and $E^{\prime}$, are relatively small. Because $F_{s}^{\prime}$ is symmetric to the equator, the asymmetry of the tropical precipitation anomalies are affected only by the effects associated with $M^{\prime}$ and the effect of $-\langle\mathbf{v} \cdot \nabla q\rangle^{\prime}$ or $-\langle\mathbf{v} \cdot \nabla(T+q)\rangle^{\prime}$. From the analysis of the QTCM simulations, the rich-get-richer mechanism and the nonlinear effect of the vertical moisture transport induce positive tropical precipitation anomalies over the summer (Southern) hemisphere. Note that both effects are associated with $M^{\prime}$. On the other hand, the effect of either the horizontal moisture or MSE transport, which includes the upped-ante mechanism, the anomalous wind mechanism, and the nonlinear effect of the horizontal MSE transport, induces the negative tropical precipitation anomalies over the winter (Northern) hemisphere.

\section{ENSO impacts on local and remote areas}

The main forcing of ENSO are the SST anomalies over the equatorial eastern Pacific, which are relatively localized, so the eastern Pacific precipitation should be strongly influenced by the local SST anomalies. The ENSO SST anomalies also induce relatively uniform responses in the tropical tropospheric temperature via moist convective interaction with wave dynamics (Chiang and Sobel 2002; Su and Neelin 2002; Wallace et al. 1998), so ENSO can affect tropical precipitation in regions away from the equatorial eastern Pacific via the tropospheric temperature changes (Chiang and Sobel 2002; NCS03). In this section, we discuss the ENSO impacts on tropical precipitation over local and remote areas, respectively. Note that the local area is the tropical eastern Pacific $\left(170^{\circ}-120^{\circ} \mathrm{W}\right)$ and the remote area is regions outside the tropical eastern Pacific.

\section{a. Local area}

To examine the local SST effect over the eastern Pacific, anomalies between $170^{\circ}$ and $120^{\circ} \mathrm{W}$, which is the range of the Niño-3.4 region, are averaged and the results are shown in Fig. 9. The warm SST anomalies are spatially symmetric to the equator and temporally symmetric to the El Niño peak phase (December of year 0-January of year 1). The warm tropospheric temperature anomalies are also spatially and temporally symmetric, but the maximum anomalies occur around February of year 1, which is a lag of 1 month to the maximum SST anomalies. The warm tropospheric temperature anomalies expand farther poleward than the corresponding SST anomalies. The maximum tropospheric temperature anomalies are around $15^{\circ}$ latitude in both hemispheres, while the maximum SST anomalies are at the equator. This relation between two anomalous temperature patterns indicates a Rossby wave response of tropospheric temperature anomalies to the SST anomalies, so the local tropospheric temperature anomalies are rather a response to the local warm SST anomalies than a forcing itself.

The corresponding positive precipitation anomalies start from the Northern Hemisphere around July of year 0 , gradually move to the Southern Hemisphere, and reach their maximum strength around FebruaryMarch of year 1, which is almost the same time as that of the maximum tropospheric temperature anomalies. The precipitation anomalies disappear around July of year 1. To the north of these positive precipitation anomalies, relatively narrow and weak negative precipitation anomalies are also found. Thus, an asymmetric pattern of tropical precipitation anomalies is found over the tropical eastern Pacific, but the amplitude of the positive precipitation anomalies over the Southern Hemisphere is much stronger than the negative precipitation anomalies over the Northern Hemisphere. This asymmetry in the precipitation anomalies is consistent with the change of the local Hadley circulation (Fig. 10a). Strong anomalous ascending motion is found over the Southern Hemisphere, while weak anomalous descending motion is found over the Northern Hemisphere. The asymmetry of the precipitation anomalies may be associated with the southward shift of ITCZ over the eastern Pacific (Halpern and Hung 2001) and a double ITCZ over the eastern Pacific (Gu et al. 2005). A similar pattern is also found for the tropospheric moisture anomalies (Fig. 9d). Both positive precipitation and moisture anomalies occur much earlier than those zonally averaged anomalies shown in Fig. 2, and they are roughly symmetric to their respective peak phases. In other words, the temporal asymmetry found in the zonal average $\left(0^{\circ}-360^{\circ}\right)$ of the precipitation anomalies (Fig. 2c) does not come from changes over the local area, which is dominated by the local maximum SST anomalies. 
(a) SST': $(190-240)$

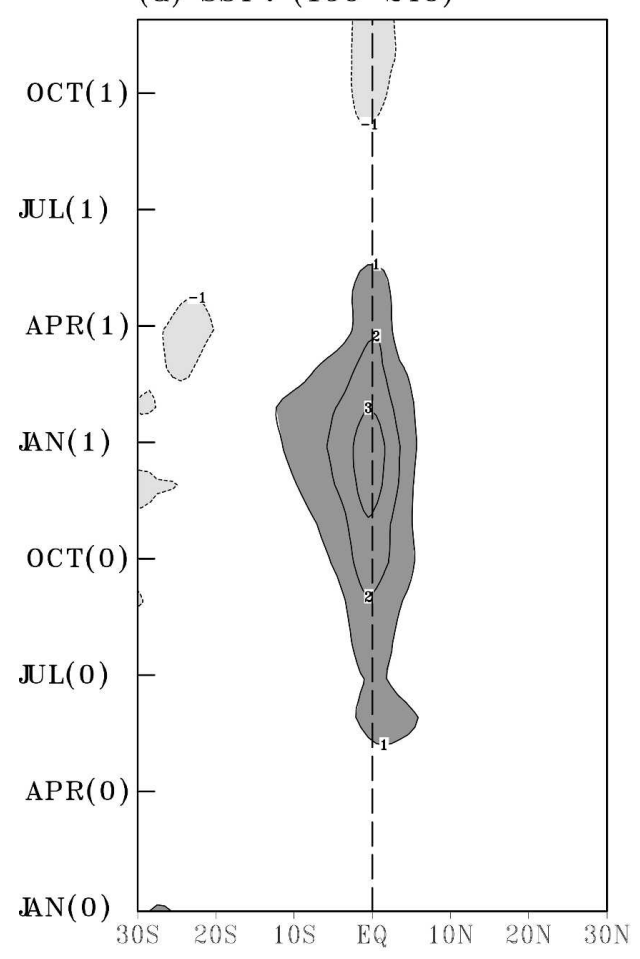

(c) $\mathrm{p}^{\prime}$

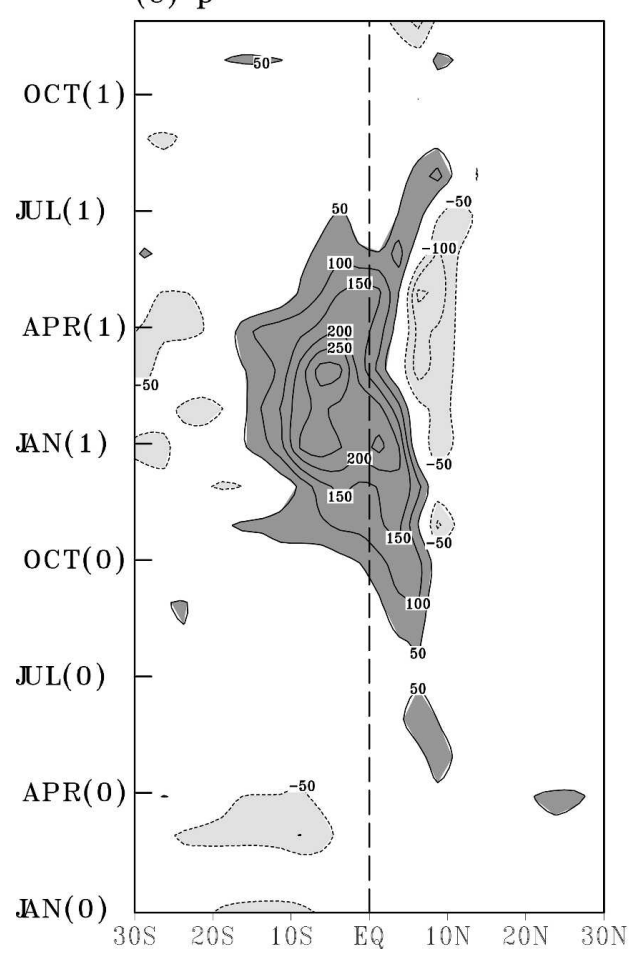

(b) $\mathrm{Ta}^{\prime}$

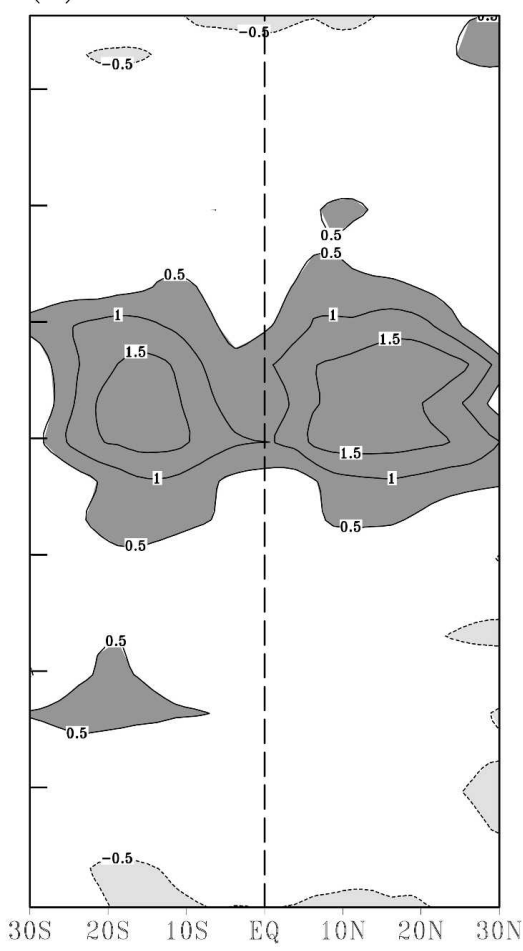

(d) q' (NCEP2)

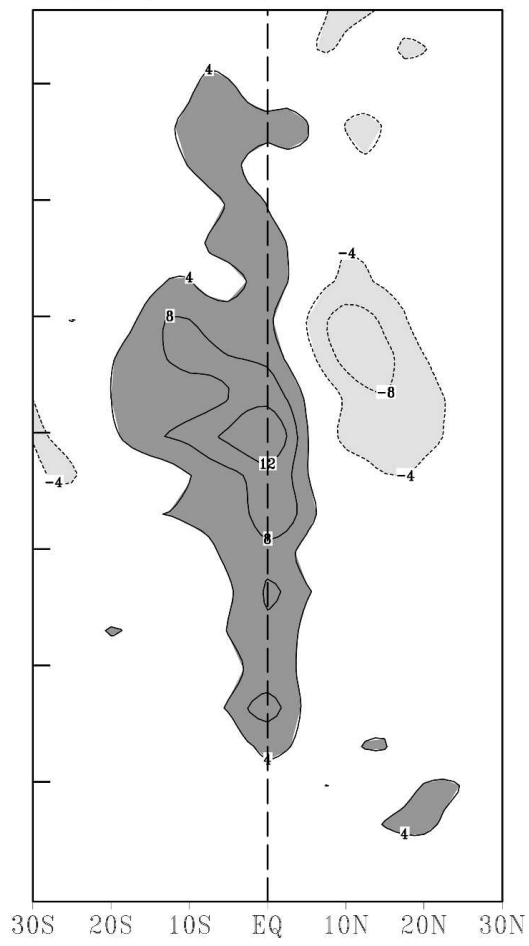

FIG. 9. Same as Fig. 2, but for averages over the local area of $170^{\circ}-120^{\circ} \mathrm{W}$. 
(a) $\operatorname{FMA}(1) \mathrm{w}^{\prime}(190-240)$

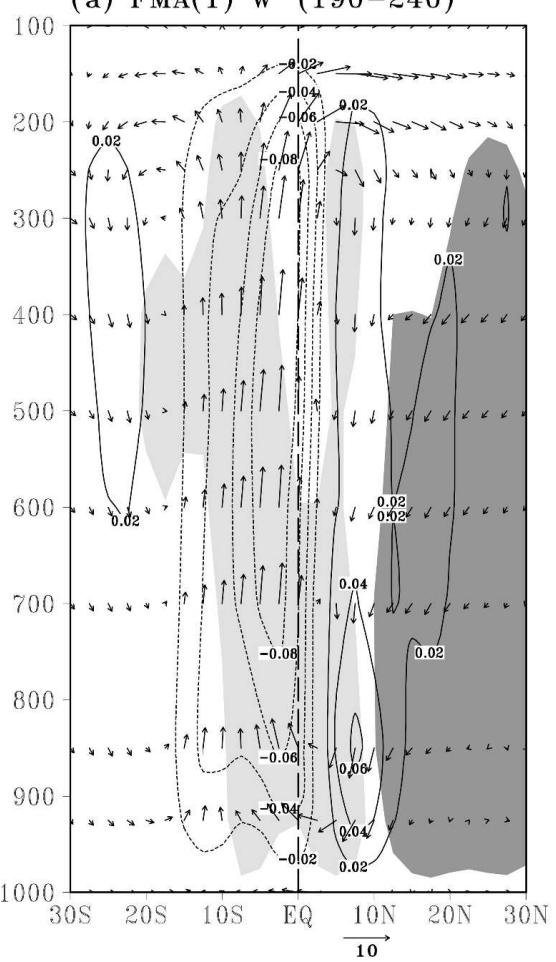

(b) $w^{\prime}(0-360)-(190-240)$

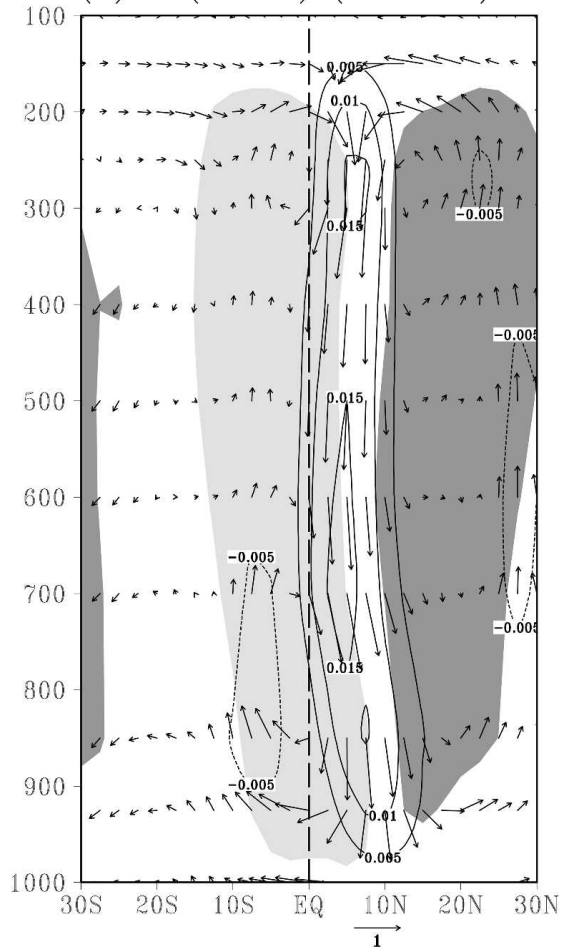

FIG. 10. Same as Fig. 6, but for averages over the (a) local and (b) remote areas.

\section{b. Remote area}

To examine the changes over the remote area, anomalies are averaged outside the local region of $170^{\circ}-120^{\circ} \mathrm{W}$, and the results are shown in Fig. 11 . The warm SST anomalies become asymmetric to the equator, with most positive anomalies over the Southern Hemisphere and negative anomalies over the Northern Hemisphere. However, this SST asymmetry does not show any meridional movement. For the temporal variation, the anomalies occur around September of year 0 and end around August of year 1, so the SST anomalies shift toward the El Niño decaying phase (year 1). The amplitude of the warm SST anomalies is not only much weaker than the local SST anomalies, but is also relatively weaker than the corresponding tropospheric temperature anomalies (Fig. 11b). The distribution of tropospheric temperature anomalies over the remote area is also different from anomalies over the local area. Spatially, they are roughly symmetric to the equator with a slightly stronger amplitude over the Northern Hemisphere. Temporally, the growing rate of the tropical temperature anomalies is much faster than the decaying rate, so there is no temporal symmetry such as those found in the local area. The warm tropospheric temperature anomalies start in December of year 0 and end around August of year 1, shifting to year 1 much more than the corresponding SST anomalies shown in Fig. 11a.

The corresponding precipitation anomalies show very strong spatial asymmetry, which has a similar seasonal variation to the mean tropical convection. Unlike the asymmetry in the local region $\left(170^{\circ}-120^{\circ} \mathrm{W}\right)$, the negative precipitation anomalies over the Northern Hemisphere are stronger than their counterpart-the positive precipitation anomalies over the Southern Hemisphere. This is also consistent with the anomalous Hadley circulation: weak anomalous ascending motion is over the Southern Hemisphere and strong anomalous descending motion is over the Northern Hemisphere. The different strengths of the anomalous vertical motion between local and remote areas are due to the anomalous Walker circulation induced by El Niño. The precipitation anomalies occur in October of year 0 and end around August of year 0, so the precipitation anomalies over the remote region show an asymmetric pattern between the El Niño growing and decaying phases. This temporal asymmetry does not occur for the local region between $170^{\circ}$ and $120^{\circ} \mathrm{W}$, which implies that the temporal asymmetry of the tropical precipitation anomalies shown in Figs. 1b and 2c mainly comes from the remote region. The tropospheric moisture anomalies also show a similar temporal and spatial pat- 

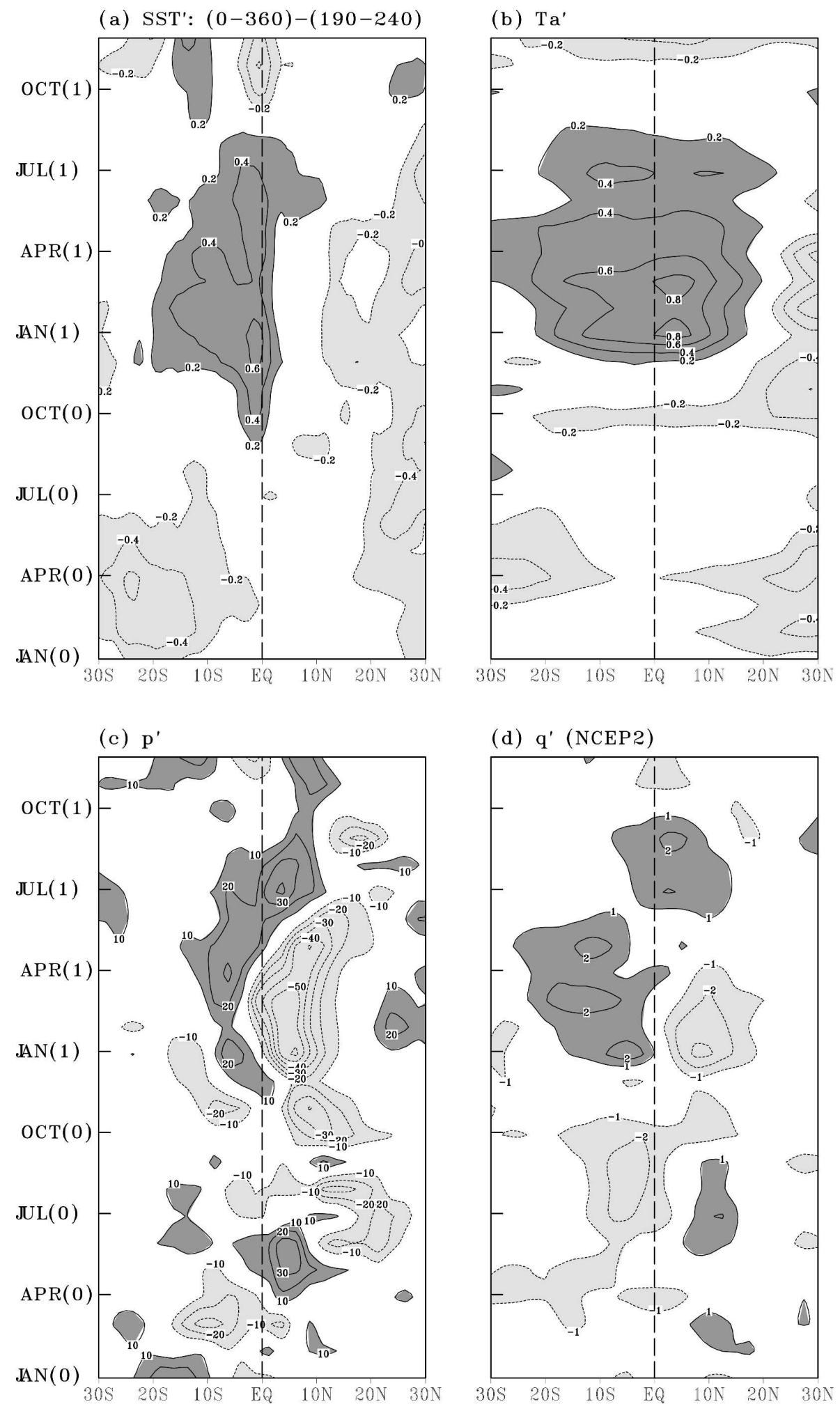

FIG. 11. Same as Fig. 9, but for averages over the remote region outside of the local area. 
(a) $\mathrm{P}^{\prime}($ remote $\mathrm{SST})$

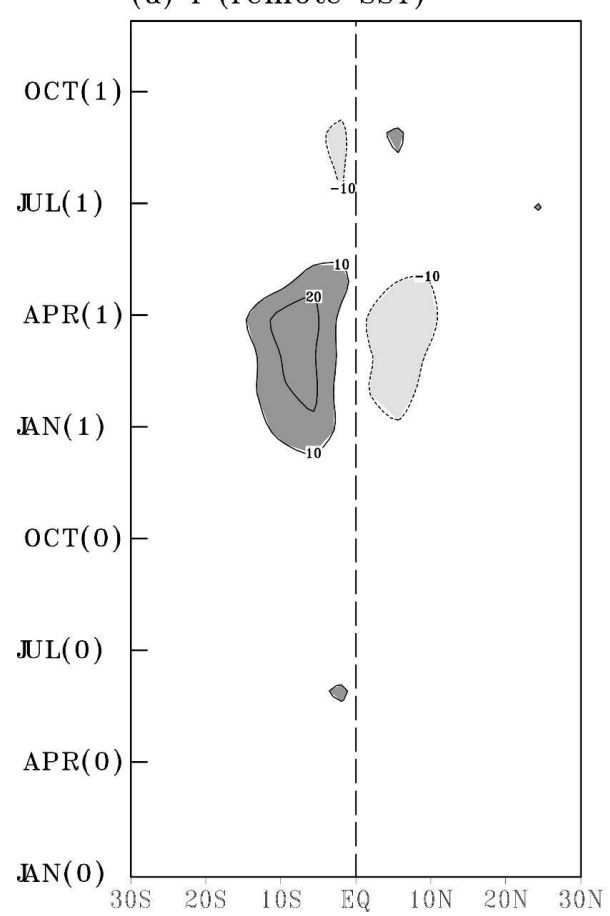

(b) $\mathrm{P}^{\prime}(\mathrm{CAPE})$

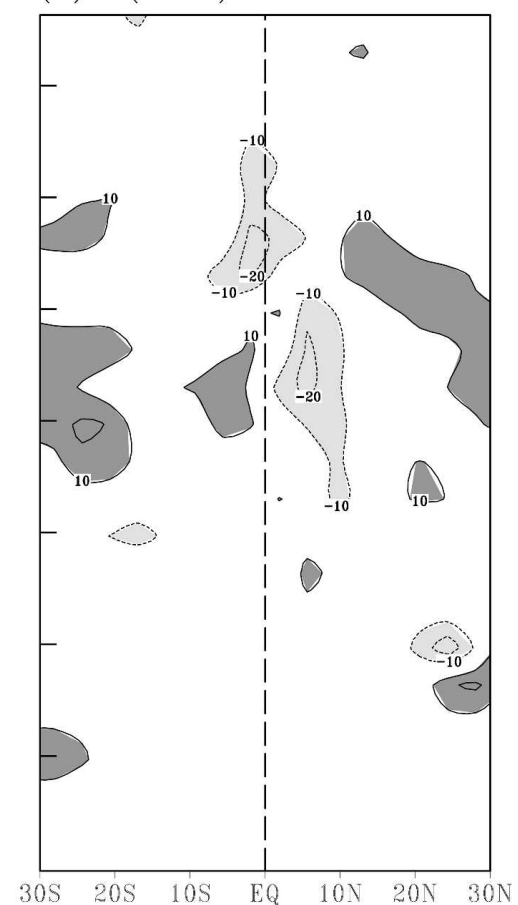

FIG. 12. The precipitation anomalies for the (a) remote SST and (b) CAPE runs.

tern to the tropical precipitation anomalies, but the moisture anomalies are over wider regions and have a smoother gradient (Fig. 11d).

As discussed above, the temporal asymmetry of the zonally averaged tropical precipitation anomalies are from the remote region, so the warm El Niño SST anomalies over the equatorial eastern Pacific cannot directly cause this temporal asymmetry. Several studies (Chiang and Sobel 2002; Su and Neelin 2002) show that the tropical precipitation anomalies over the remote region can be induced by moist convective interaction with wave dynamics and air-sea coupling feedbacks. To examine these processes, two pairs of experiments forced by the SST and tropospheric temperature anomalies over the remote area are performed respectively. The first pair of experiments is the remote SST experiments, which use the prescribed SST anomalies over the remote area (Fig. 11a) and the climatological SST over the local region. Figure 12a shows the corresponding precipitation anomalies. A clear asymmetric pattern of the precipitation anomalies starts in December of year 0 and ends around June of year 1. The SST anomalies over the remote region induce an asymmetry of the tropical precipitation anomalies. In a sensitivity test with symmetric SST anomalies, the precipitation anomalies are still similar to Fig. 12a, but with weaker amplitudes (not shown). This indicates that the precipi- tation asymmetry is not induced solely by the asymmetric SST anomalies. The second pair of experiments is the CAPE experiments, which use the tropospheric temperature anomalies over the remote area (Fig. 11b). The corresponding precipitation anomalies are shown in Fig. 12b. A similar asymmetry of the precipitation anomalies is also found in December of year 0-April of year 1 , with positive anomalies over the Southern Hemisphere and negative anomalies over the Northern Hemisphere. Both SST and tropospheric temperature anomalies over the remote area occur mostly in year 1 (Figs. 11a and 11b), so the spatial asymmetry of the tropical precipitation anomalies is found only in year 1 . Thus, the temporal asymmetry is caused by the remote SST and tropospheric temperature anomalies.

\section{Discussion and conclusions}

In this study, the focus is on how a circulation, such as the Hadley circulation, and the associated precipitation respond to a similar forcing over its ascending and descending branch. Here, the ENSO case is used as an example. From a zonally averaged point of view, the ENSO SST anomalies and the corresponding $F_{s}^{\prime}$ are spatially symmetric, with the same sign of anomalies on both sides of the equator. If there were no forcing other than the SST anomalies, the zonally averaged tropical 


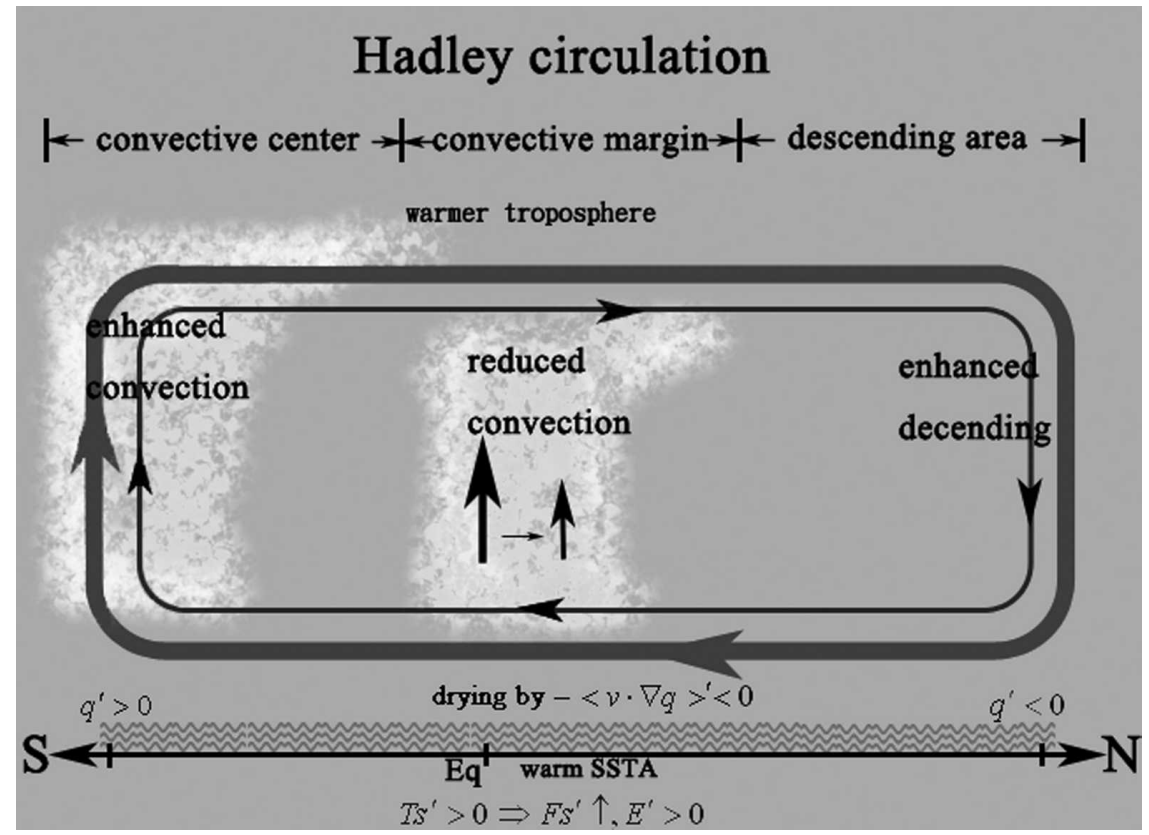

FIG. 13. A schematic diagram of mechanisms inducing the asymmetry of the tropical precipitation anomalies.

precipitation anomalies should also be spatially symmetric. However, this is not what we found in the observations. The zonal average of the observed tropical precipitation anomalies shows an asymmetric pattern, with positive anomalies over the summer hemisphere and negative anomalies over the winter hemisphere. This asymmetric pattern reaches its maximum strength in the spring of the ENSO decaying phase (year 1). The movement of the precipitation asymmetry is consistent with the seasonal migration of the Hadley circulation. Thus, the Hadley circulation is enhanced (reduced) by the symmetric El Niño (La Niña) SST anomalies, with positive (negative) precipitation anomalies over convective regions, the ascending branch of the Hadley circulation, and negative (positive) precipitation anomalies over margins of convective regions.

Figure 13 is a schematic diagram that explains how ENSO induces the asymmetry of the tropical precipitation. In an El Niño event, the warm SST anomalies over the tropical eastern Pacific enhance the local convection via $F_{s}^{\prime}$, that is, $F^{\text {net' }}>0$, and moisten the lower troposphere via the evaporation process. Meanwhile, the enhanced convection warms the entire tropical troposphere through wave dynamics (Chiang and Sobel 2002; Su and Neelin 2002; Wallace et al. 1998). The warmer tropical troposphere also increases low-level moisture over convective regions under a convective QE. This linking of low-level moisture and tropospheric temperature is termed "QE mediation" (Neelin and Su 2005; Chou et al. 2006). Note that the QE mediation does not affect low-level moisture over nonconvective regions, so it creates a meridional gradient of the low-level moisture anomalies between convective and nonconvective regions. The increased low-level moisture decreases the effective moist stability $M$, so convection and the associated tropical precipitation are enhanced further over convective regions. The enhanced low-level moisture and ascending motion also increase the precipitation over convective regions via the nonlinear effect of the vertical moisture transport

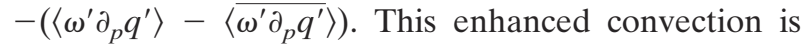
over the ascending branch of the Hadley circulation, so the Hadley circulation is strengthened. The strengthened Hadley circulation increases downward motion over its descending branch. This anomalous downward motion dries the low-level moisture over nonconvective regions, so the meridional gradient of the low-level moisture anomalies is enhanced, with positive moisture anomalies over the ascending area and negative precipitation anomalies over the descending area. This moisture gradient, combined with the mean Hadley circulation, induces a dry advection at lower troposphere, that is, $-\overline{\mathbf{v}} \cdot \nabla q^{\prime}<0$. This dry advection, similar to the upped-ante mechanism (CN04), reduces precipitation over the northern margins of convection zones. On the other hand, the anomalous Hadley circulation also imports dry air from higher latitudes to the convective margins via $-\mathbf{v}^{\prime} \cdot \nabla \bar{q}$ and reduces the precipitation over 
these regions. The nonlinear effect of the horizontal moisture transport $-\left(\left\langle\mathbf{v}^{\prime} \cdot \nabla q^{\prime}\right\rangle-\left\langle\overline{\mathbf{v}^{\prime} \cdot \nabla q^{\prime}}\right\rangle\right)$ also suppresses convection over the convective margins. The temperature advection $-\langle\mathbf{v} \cdot \nabla T\rangle^{\prime}$ has a similar but weaker effect on the tropical precipitation. Overall, the symmetric warm SST anomalies initiate positive tropical precipitation anomalies via $F_{s}^{\prime}$. However, two effects associated with the Hadley circulation-the effect as-

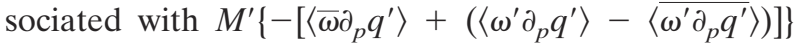
and the effect of the horizontal MSE transport $\left[-\langle\mathbf{v} \cdot \nabla(T+q)\rangle^{\prime}\right]$-create the asymmetry of the tropical precipitation anomalies that follows the seasonal migration of the Hadley circulation.

The spatial asymmetry of the zonally averaged tropical precipitation anomalies shows a phase lag to the maximum SST anomalies over the tropical eastern Pacific. The SST anomalies show a temporally symmetric variation with the maximum amplitude around January of year 1 (Fig. 1a), while the asymmetry of the tropical precipitation occurs mainly in the ENSO decaying phase (year 1). This inconsistency provides evidence that SST anomalies over the tropical eastern Pacific do not directly induce the spatial asymmetry of the tropical precipitation anomalies. In our analysis, the spatial asymmetry of the tropical precipitation anomalies is mainly from precipitation anomalies over the remote area outside of the tropical eastern Pacific. Those remote precipitation anomalies are affected by the SST and tropospheric temperature anomalies over the same remote region. Both the maximum SST and tropospheric temperature anomalies over the remote area have a one-season lag to the maximum SST anomalies over the local area (e.g., Chiang and Lintner 2005; Kumar and Hoerling 2003; Su et al. 2005).

The weak asymmetric SST anomalies in 1982-83 (Fig. 2a) may also induce the asymmetry of the tropical precipitation anomalies, but are not the main cause for this precipitation asymmetry. In a sensitivity test with symmetric SST anomalies, the asymmetry of the tropical precipitation anomalies can still be produced. Moreover, the 1999/2000 La Niña case has symmetric SST anomalies, but the corresponding precipitation anomalies show a clear seasonal movement that is consistent with the migration of the Hadley circulation. This implies that the precipitation asymmetry can be created without asymmetric SST anomalies.

The moisture budget is more accurate than the MSE budget because of the independence of the moisture budget to convection height. The variation of $M^{\prime}$ involves a significant cancellation between two large effects: the low-level moisture effect and the maximum depth of convection effect (Yu et al. 1998). The lack of a definite theory for $M^{\prime}$ creates caveats in determining the effect associated with $M^{\prime}$. Accurately estimating the $M^{\prime}$ effect presents a substantial challenge and is subject to future study. Here we focus only on some key terms that can be identified with particular effects. Our analysis does show evidence that the effect associated with $M^{\prime}$, which depends only on the low-level moisture effect $-\left\langle\bar{\omega} \partial_{p} q^{\prime}\right\rangle$ in this study because of neglecting the contribution of $\left\langle\omega \partial_{p} s\right\rangle$, does indeed affect the positive precipitation anomalies in the asymmetry of the tropical precipitation anomalies.

In our analysis for inducing the asymmetry of the zonally averaged tropical precipitation anomalies during ENSO, two effects responsible for the asymmetry are similar to the rich-get-richer and upped-ante mechanisms found in the global warming simulations of the simplified model of intermediate complexity (CN04) and the comprehensive coupled general circulation model (Chou et al. 2006). This study provides evidence that these two effects found in the global warming study exist not only in the model simulations, but also in the observations. In global warming, the main forcing is also symmetric to the equator, but with a much broader spatial scale. Thus, their impacts on atmospheric circulations, such as the Hadley and Walker circulations, via the processes discussed here should be more pronounced. The further analysis in the global warming case will be discussed in another study.

Acknowledgments. This work was supported under the National Science Council Grant 94-2111-M-001001. The authors thank Dr. Jien-Yi Tu for preparing the observations and Ms. Pei-Sam Sun and Ms. Yan-Shih Lin for graphics. Comments from Dr. Adam H. Sobel and an anonymous reviewer were helpful for improving the quality of this paper.

\section{REFERENCES}

Adler, R. F., and Coauthors, 2003: The version-2 global precipitation climatology project (GPCP) monthly precipitation analysis (1979-present). J. Hydrometeor., 4, 1147-1167.

Betts, A. K., and M. J. Miller, 1993: The Betts-Miller scheme. The Representation of Cumulus Convection in Numerical Models of the Atmosphere, Meteor. Monogr., No. 46, Amer. Meteor. Soc., 107-121.

Chang, C.-P., Z. Wang, J. Ju, and T. Li, 2004: On the relationship between western Maritime Continent monsoon rainfall and ENSO during northern winter. J. Climate, 17, 665-672.

Chiang, J. C. H., and A. H. Sobel, 2002: Tropical tropospheric temperature variations caused by ENSO and their influence on the remote tropical climate. J. Climate, 15, 2616-2631.

—, and B. R. Lintner, 2005: Mechanisms of remote tropical surface warming during El Niño. J. Climate, 18, 4130-4149.

_, Y. Kushnir, and A. Giannini, 2002: Deconstructing Atlantic Intertropical Convergence Zone variability: Influence of the local cross-equatorial sea surface temperature gradient and 
remote forcing from the eastern equatorial Pacific. J. Geophys. Res., 107, 4004, doi:10.1029/2000JD000307.

Chou, C., and J. D. Neelin, 1996: Linearization of a longwave radiation scheme for intermediate tropical atmospheric models. J. Geophys. Res., 101, 15 129-15 145.

— , and — 1999: Cirrus detrainment-temperature feedback. Geophys. Res. Lett., 26, 1295-1298.

__ and _ - 2004: Mechanisms of global warming impacts on regional tropical precipitation. J. Climate, 17, 2688-2701.

- _ _ , and H. Su, 2001: Ocean-atmosphere-land feedbacks in an idealized monsoon. Quart. J. Roy. Meteor. Soc., 127, 18691891.

$\longrightarrow,-$ J.-Y. Tu, and C.-T. Chen, 2006: Regional tropical precipitation change mechanisms in ECHAM4/OPYC3 under global warming. J. Climate, 19, 4207-4223.

Curtis, S., and R. F. Adler, 2003: Evolution of El Niñoprecipitation relationships from satellites and gauges. J. Geophys. Res., 108, 4153, doi:10.1029/2002JD002690.

Dai, A., and T. M. L. Wigley, 2000: Global patterns of ENSOinduced precipitation. Geophys. Res. Lett., 27, 1283-1286.

Foley, J. A., A. Botta, M. T. Coe, and M. H. Costa, 2002: El NiñoSouthern oscillation and the climate, ecosystems and rivers of Amazonia. Global Biogeochem. Cycles, 16, 1132, doi:10.1029/ 2002GB001872.

Fu, Q., and K. N. Liou, 1993: Parameterization of the radiative properties of cirrus clouds. J. Atmos. Sci., 50, 2008-2025.

Giannini, A., J. C. H. Chiang, M. A. Cane, Y. Kushnir, and R. Seager, 2001: The ENSO teleconnection to the Tropical Atlantic Ocean: Contribution of the remote and local SSTs to rainfall variability. J. Climate, 14, 4530-4544.

Gu, G., R. F. Adler, and A. H. Sobel, 2005: The eastern Pacific ITCZ during the boreal spring. J. Atmos. Sci., 62, 1157-1174.

Halpern, D., and C.-W. Hung, 2001: Satellite observations of the southeast Pacific intertropical convergence zone during 1993-1998. J. Geophys. Res., 106, 28 107-28 112.

Harshvardhan, R. Davies, D. A. Randall, and T. G. Corsetti, 1987: A fast radiation parameterization for general circulation models. J. Geophys. Res., 92, 1009-1016.

Hendon, H. H., 2003: Indonesian rainfall variability: Impacts of ENSO and local air-sea interaction. J. Climate, 6, 1775-1790.

Jiang, Z., G. T.-J. Chen, and M.-C. Wu, 2003: Large-scale circulation patterns associated with heavy spring rain events over Taiwan in strong ENSO and non-ENSO years. Mon. Wea. Rev., 131, 1769-1782.

Kanamitsu, M., W. Ebisuzaki, J. Woollen, S.-K. Yang, J. J. Hnilo, M. Fiorino, and G. L. Potter, 2002: NCEP-DOE AMIP-II Reanalysis (R-2). Bull. Amer. Meteor. Soc., 83, 1631-1643.

Kiehl, J. T., 1994: On the observed near cancellation between longwave and shortwave cloud forcing in tropical regions. $J$. Climate, 7, 559-565.

Kiladis, G., and H. Diaz, 1989: Global climatic anomalies associated with extremes in the Southern Oscillation. J. Climate, 2, 1069-1090.

Kumar, A., and M. P. Hoerling, 2003: The nature and causes for the delayed atmospheric response to El Niño. J. Climate, 16, 1391-1403.

Lau, N.-C., and M. J. Nath, 2003: Atmosphere-ocean variations in the Indo-Pacific sector during ENSO episodes. J. Climate, 16, 3-20.

McBride, J. L., and N. Nicholls, 1983: Seasonal relationships between Australian rainfall and the Southern Oscillation. Mon. Wea. Rev., 111, 1998-2004.

Mears, C. A., M. C. Schabel, and F. J. Wentz, 2003: A reanalysis of the MSU channel 2 tropospheric temperature record. $J$. Climate, 16, 3650-3664.

Neelin, J. D., and J.-Y. Yu, 1994: Modes of tropical variability under convective adjustment and the Madden-Julian Oscillation. Part I: Analytical theory. J. Atmos. Sci., 51, 1876-1894.

—- and N. Zeng, 2000: A quasi-equilibrium tropical circulation model-Formulation. J. Atmos. Sci., 57, 1741-1766.

, and H. Su, 2005: Moist teleconnection mechanisms for the tropical South American and Atlantic sector. J. Climate, 18, 3928-3950.

, C. Chou, and H. Su, 2003: Tropical drought regions in global warming and El Niño teleconnections. Geophys. Res. Lett., 30, 2275, doi:10.1029/2003GL018625.

Nobre, P., and J. Shukla, 1996: Variations of sea surface temperature, wind stress, and rainfall over the tropical Atlantic and South America. J. Climate, 9, 2464-2479.

Ramanathan, V., R. D. Cess, E. F. Harrison, P. Minnis, B. R. Barkstrom, E. Ahmad, and D. Hartmann, 1989: Cloudradiative forcing and climate: Results from the earth radiation budget experiment. Science, 243, 57-63.

Randel, D. L., T. H. Vonder Haar, M. A. Ringerud, G. L. Stephens, T. J. Greenwald, and C. L. Combs, 1996: A new global water vapor dataset. Bull. Amer. Meteor. Soc., 77, 1233-1246.

Rasmusson, E. M., and T. H. Carpenter, 1982: Variations in tropical sea surface temperature and surface wind fields associated with the Southern Oscillation/El Niño. Mon. Wea. Rev., 110, 354-384.

— , and P. A. Arkin, 1993: A global view of large-scale precipitation variability. J. Climate, 6, 1495-1521.

Reynolds, R. W., N. A. Rayner, T. M. Smith, D. C. Stokes, and W. Wang, 2002: An improved in situ and satellite SST analysis for climate. J. Climate, 15, 1609-1625.

Ropelewski, C. F., and M. S. Halpert, 1987: Global and regional scale precipitation associated with El Niño/Southern Oscillation. Mon. Wea. Rev., 115, 1606-1626.

— , and - 1996: Quantifying Southern Oscillation-precipitation relationships. J. Climate, 9, 1043-1059.

Seager, R., N. Harnik, W. A. Robinson, Y. Kushnir, M. Ting, H.-P. Huang, and J. Velez, 2005: Mechanisms of ENSOforcing of hemispherically symmetric precipitation variability. Quart. J. Roy. Meteor. Soc., 131, 1501-1527.

Sobel, A. H., I. M. Held, and C. S. Bretherton, 2002: The ENSO signal in tropical tropospheric temperature. J. Climate, 15, 2702-2706.

Soden, B. J., 2000: The sensitivity of the tropical hydrological cycle to ENSO. J. Climate, 13, 538-549.

Stevens, B., J. Duan, J. C. McWilliams, M. Münnich, and J. D. Neelin, 2002: Entrainment, Rayleigh friction, and boundary layer winds over the tropical Pacific. J. Climate, 15, 30-44.

Su, H., and J. D. Neelin, 2002: Teleconnection mechanisms for tropical Pacific descent anomalies during El Niño. J. Atmos. Sci., 59, 2682-2700.

,-- , and C. Chou, 2001: Tropical teleconnection and local response to SST anomalies during the 1997-1998 El Niño. $J$. Geophys. Res., 106, 20 025-20 043.

,-- , and J. E. Meyerson, 2005: Mechanisms for lagged atmospheric response to ENSO SST forcing. J. Climate, 18, 4194-4215.

Trenberth, K. E., G. W. Branstator, D. Karoly, A. Kumar, N.-C. Lau, and C. Ropelewski, 1998: Progress during TOGA in understanding and modeling global teleconnections associ- 
ated with tropical sea surface temperatures. J. Geophys. Res., 103, 14 291-14 324.

Uppala, S. M., and Coauthors, 2005: The ERA-40 Reanalysis. Quart. J. Roy. Meteor. Soc., 131, 2961-3012.

Wallace, J. M., E. M. Rasmusson, T. P. Mitchell, V. E. Kousky, E. S. Sarachik, and H. von Storch, 1998: On the structure and evolution of ENSO-related climate variability in the tropical Pacific: Lessons from TOGA. J. Geophys. Res., 103, $14241-$ 14260.

Wang, B., R. Wu, and X. Fu, 2000: Pacific-East Asian teleconnection: How does ENSO affect East Asian climate? J. Climate, 13, 1517-1536.

Xie, P., and P. A. Arkin, 1997: Global precipitation: A 17-year monthly analysis based on gauge observations, satellite estimates, and numerical outputs. Bull. Amer. Meteor. Soc., 78, $2539-2558$

Yu, J.-Y., and J. D. Neelin, 1994: Modes of tropical variability under convective adjustment and the Madden-Julian oscillation. Part II: Numerical results. J. Atmos. Sci., 51, 1895-1914.

- C. Chou, and J. D. Neelin, 1998: Estimating the gross moist stability of the tropical atmosphere. J. Atmos. Sci., 55, 13541372

Zeng, N., J. D. Neelin, and C. Chou, 2000: A quasi-equilibrium tropical circulation model-Implementation and simulation. J. Atmos. Sci., 57, 1767-1796. 
Copyright of Journal of Climate is the property of American Meteorological Society and its content may not be copied or emailed to multiple sites or posted to a listserv without the copyright holder's express written permission. However, users may print, download, or email articles for individual use. 